ANL-6828

Propulsion Systems and Energy Conversion (TID-4500, 37th Ed.)

AEC Research and

Development Report

ARGONNE NATIONAL LABORATORY

9700 South Cass Avenue

Argonne, Illinois 60440

\title{
PRELIMINARY PHYSICS AND HEAT TRANSFER DESIGN CALCULATIONS FOR A ROCKET FUEL TEST REACTOR (RFTR)
}

by

D. R. MacFarlane and J. T. Madell

Reactor Physics Division

August 1964

Operated by The University of Chicago under

Contract W-31-109-eng-38 with the

U. S. Atomic Energy Commission 


\section{DISCLAIMER}

This report was prepared as an account of work sponsored by an agency of the United States Government. Neither the United States Government nor any agency Thereof, nor any of their employees, makes any warranty, express or implied, or assumes any legal liability or responsibility for the accuracy, completeness, or usefulness of any information, apparatus, product, or process disclosed, or represents that its use would not infringe privately owned rights. Reference herein to any specific commercial product, process, or service by trade name, trademark, manufacturer, or otherwise does not necessarily constitute or imply its endorsement, recommendation, or favoring by the United States Government or any agency thereof. The views and opinions of authors expressed herein do not necessarily state or reflect those of the United States Government or any agency thereof. 


\section{DISCLAIMER}

Portions of this document may be illegible in electronic image products. Images are produced from the best available original document. 
-

2

2

-

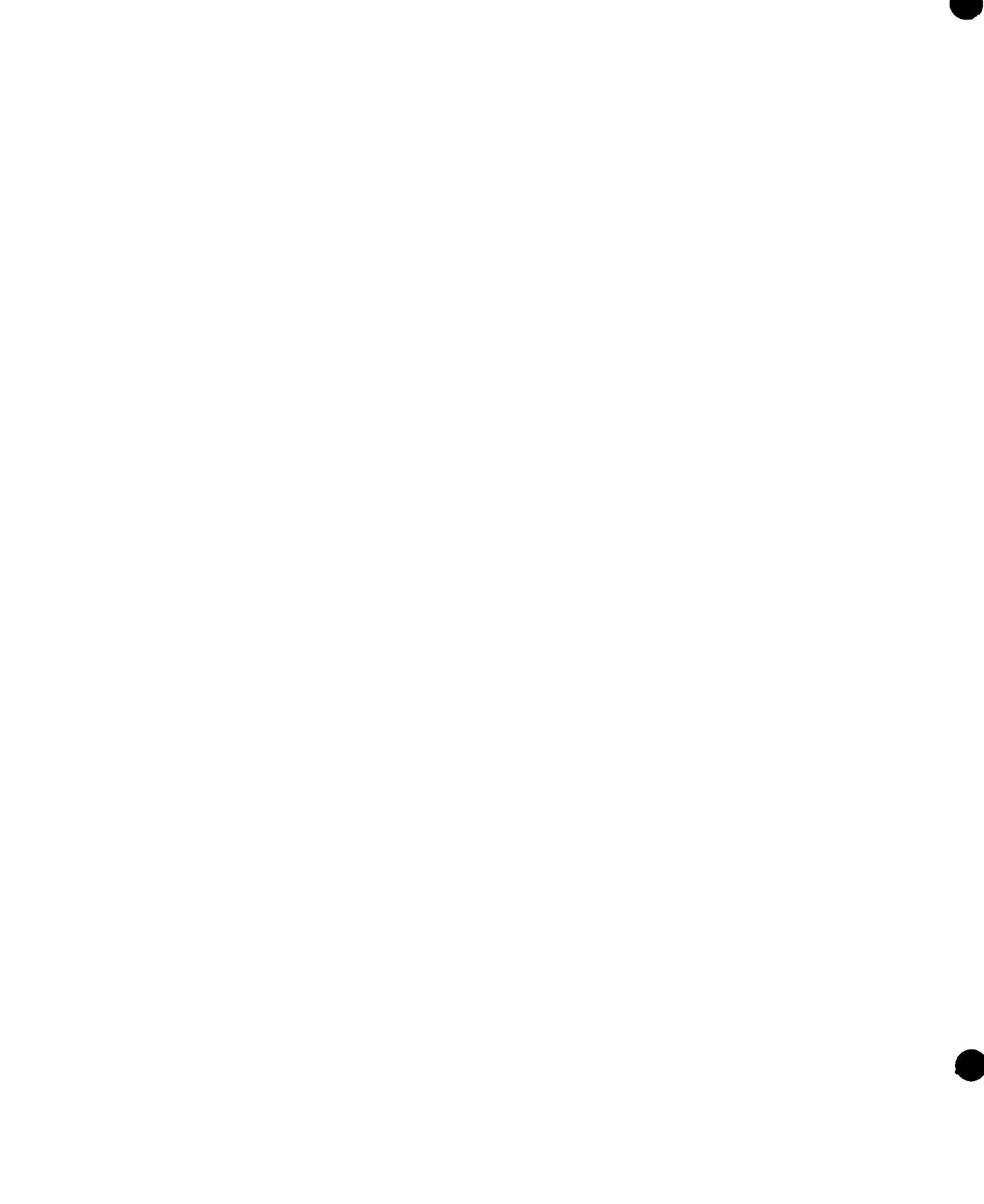


TABLE OF CONTENTS

$\underline{\text { Page }}$

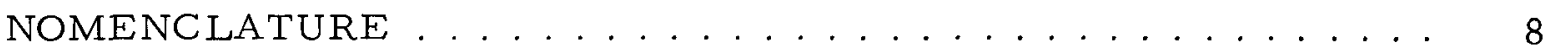

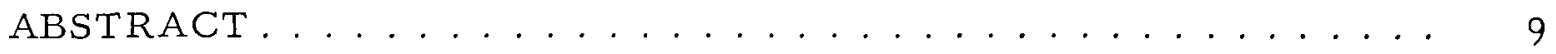

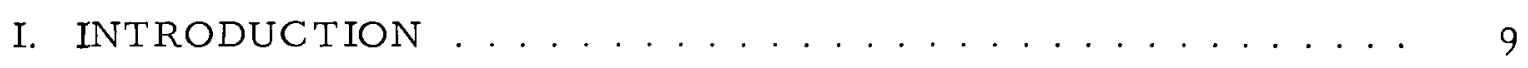

II. PHYSICS CALCULATIONS . . . . . . . . . . . . . 10

A. Survey Calculations in Spherical Geometry. . . . . . . . 11

B. Calculations in Infinite Cylindrical Geometry . . . . . . 15

C. Calculations in Finite Cylindrical Geometry . . . . . . . 22

III. HEAT REMOVAL FROM TEST REACTOR CORES . . . . . . . . 32

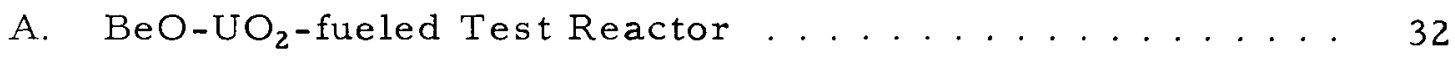

B. U-Zr Alloy Fueled Test Reactor . . . . . . . . . . . 38

IV. CONCLUSIONS OF THE STUDY. . . . . . . . . . . . . . 39

APPENDIX A: Scope of Testing Programs Required to Assure a Given Reliability for a Nuclear Rocket Engine. . . . 41

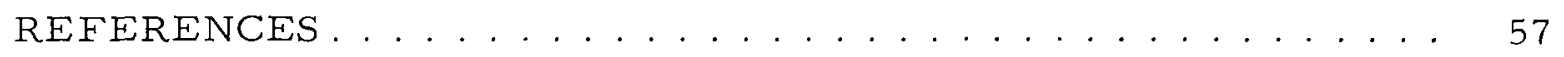




\section{LIST OF FIGURES}

No.

Title

$\underline{\text { Page }}$

1 Relative Power Density Versus Radius for Survey Calculations .....................

2-6 Relative Flux Versus Radius for Problems 101, 102, 103, 105 , and $111 \ldots \ldots \ldots$

7 Relative Power Density Versus Radius for Problems $111 \mathrm{~A}$, $112,113,114$, and 115 .

8 Relative Power Density Versus Radius for Berylliummoderated Test Reactors (Problems 119, 121, 123, and 131)

9-10 Relative Flux Versus Radius for Beryllium-moderated

Test Reactors (Problems 119,123, and 203) ........

11 Relative Power Density Versus Radius for $\mathrm{D}_{2} \mathrm{O}$-moderated Test Reactors (Problems 125, 127, and 129)

12-13 Relative Flux Versus Radius for $\mathrm{D}_{2} \mathrm{O}$-moderated Test

Reactors (Problems 125 and 127)

14-15 Relative Power Density Versus Radius for Uranium-

Zirconium Fast Reactors with $25 \%$ and $35 \%$ Sodium . . . . .

16-17 Relative Flux Versus Radius for Uranium-Zirconium Fast

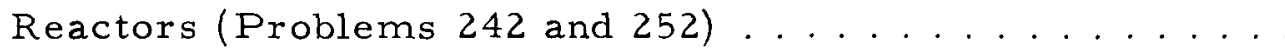

18 Power Density Ratios Versus Total Power Ratio for the Beryllium-moderated and Uranium-Zirconium Fast Test Reactors . . . . . . . . . . . . . . . . . .

19 Test Reactor Loading Versus Critical Radius for the Beryllium-moderated and the Uranium-Zirconium Fast Test Reactors . . . . . . . . . . . . . . . . .

20 Vertical Section of the Test Section, Test Reactor, and Reflector .....................

21 Computational Model of the Test Section, Test Reactor, and Radial Reflector.

22 Models of Test Section for Computing the Equivalent Height .......................

23-25 Axial Power Density for Test Section, Berylliummoderated Test Reactor and Uranium-Zirconium Fast

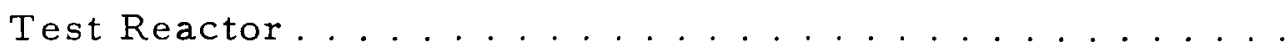




\section{LIST OF FIGURES}

No.

$\underline{\text { Title }}$

$\underline{\text { Page }}$

26-29 Relative Power Density Versus Radius for Berylliummoderated Test Reactors with 3-, 6-, 9-, and 13-cm-

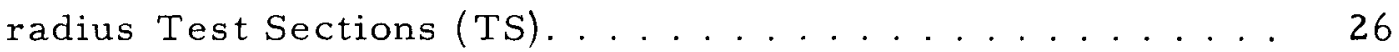

30-33 Relative Power Density Versus Radius for Fast Test

Reactors with 3-, 6-, 9-, and 13-cm-radius Test Sections (TS).

34-36 Test Reactor Power Versus Maximum Power Density

Ratio for 16-, 22-, and 30-v/o Uranium Oxide Test

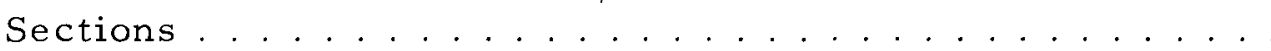

37 Maximum Cladding to Coolant Temperature Differential

Versus Coolant Outlet Temperature. . . . . . . . . . . . .

38-39 Average Power Density in Hot Channel Versus Rod

Diameter for a Beryllium Oxide-Uranium Oxide Fuel

Element with $\int \mathrm{k}(\theta) \mathrm{d} \theta$ of $100 \mathrm{~W} / \mathrm{cm}$ and $150 \mathrm{~W} / \mathrm{cm} \ldots . .$.

40-41 Temperature Profile in Hot Channel for a Beryllium Oxide-Uranium Oxide Fuel Element with a $\int k(\theta) d \theta$ of $100 \mathrm{~W} / \mathrm{cm}$ and $150 \mathrm{~W} / \mathrm{cm}$

A-1 Failure Rate Versus Lifetime for an Operating System...

A-2 Stress Spectrum for a Component during Its Useful Life

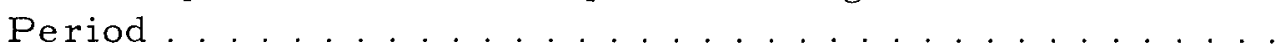

A-3 Reliability Curves . . . . . . . . . . . . . 46

A-4 Combined Effect of Chance and Wearout for $m>$ M. . . . . 47

A-5 Minutes of Testing per Operational Minute for Chance Failure Reliabilities of 0.99 and 0.95 at Various Confidence Levels. . . . . . . . . . . . . . . . . . . . .

A-6 Minutes of Testing per Operational Minute for Chance Failure Reliabilities of 0.90 and 0.80 at Various Confidence Levels.......................... 
I. Test Facility Compositions for Calculations in Spherical Geometry . . . . . . . . . . . . . .

II. Sixteen-group Energy Structure for Physics Calculations . . 12

III. Configurations for Critical Reflected Test Section in Spherical Geometry ................... 14

IV. Test Reactor Compositions for Infinite Cylinder Calculations with a $22-\mathrm{v} / 0 \mathrm{UO}_{2}$ Test Section ........... 16

V. Equivalent Heights of Test Section and Test Reactor. . . . . 24

VI. Results of Physics Calculations for a Finite Cylindrical Test Reactor with a $16-\mathrm{v} / 0 \mathrm{UO}_{2}$ Test Section. . . . . . . . 28

VII. Results of Physics Calculations for a Finite Cylindrical Test Reactor with $22-\mathrm{v} / \mathrm{O} \mathrm{UO}_{2}$ Test Section.

VIII. Results of Physics Calculations for a Finite Cylindrical Test Reactor with a $30 \mathrm{-v} / 0 \mathrm{UO}_{2}$ Test Section. . . . . . . 28

IX. Properties of Type-347 Stainless Steel at $1000^{\circ} \mathrm{F} \ldots \ldots 37$

X. Summary of Heat Transfer Calculations for $\mathrm{UO}_{2}-\mathrm{BeO}-$ fueled Test Reactor . . . . . . . . . . . . . . . 38

XI. Heat Transfer Analysis of a U-Zr Alloy-fueled Reactor for Values of Power Density and Rod Diameter . . . . . . . 38

A-1. Results of Wearout Reliability Calculations.......... 53

A-2. Results of Wearout Reliability Calculations for an Individual Component Reliability of $0.99997 \ldots \ldots \ldots \ldots \ldots$ 

1. Heat Transfer Analysis

$\mathrm{P} \quad$ reactor power, $\mathrm{MW}$

$\ell \quad$ core length, ft

D fuel rod diameter, in

$(\Delta t)_{h}$ temperature drop of film at cladding hot spot, ${ }^{\circ} \mathrm{F}$

$R_{a} \quad$ axial max/avg power density ratio

$R_{r} \quad$ radial max/avg power density ratio

$\mathrm{N}$ number of fuel rods

$\mathrm{C}_{1} \quad$ correction factor to allow for variation of heat flux with position along a coolant channel

$(\Delta t)_{m} \quad$ temperature drop of film at point of maxi mum heat flux, ${ }^{\circ} \mathrm{F}$

$\Delta t \quad$ temperature rise of coolant across core ${ }^{\circ} \mathrm{F}$

$Q \quad$ average fuel power density

Q' average core power density

$\mathrm{D}_{\mathrm{H}} \quad$ hydraulic diameter of coolant channel, in

$C_{p}$ heat capacity of coolant, $\mathrm{Btu} / \mathrm{lb}-{ }^{\circ} \mathrm{F}$

$\mu$ coolant viscosity, $\mathrm{lb} / \mathrm{hr}-\mathrm{ft}$

$\mathrm{G}$ mass flow rate of coolant, $\mathrm{lb} / \mathrm{hr}-\mathrm{ft}^{2}$

$\mathrm{t}_{2}$ coolant outlet temp, ${ }^{\circ} \mathrm{F}$ coolant inlet temp, ${ }^{\circ} \mathrm{F}$

cladding surface temperature, ${ }^{\circ} \mathrm{F}$

$x / \ell$

ractional distance

along a coolant channel

coolant volume fraction

$\int k(\theta) d \theta$ maximum fuel thermal rating, $\mathrm{W} / \mathrm{cm}$

k thermal conductivity

$\mathrm{Btu} / \mathrm{hr}-\mathrm{ft}-{ }^{\circ} \mathrm{F}$

heat transfer coefficient

Nusselt number

$\mathrm{Pe} \quad$ Peclet number

\section{Limitations Imposed by Fuel}

D fuel rod diameter, in

$\epsilon$ container wall thickness, in.

$\sigma_{t}$ thermal stress, psi

E Young's modulus, psi Poisson's ratio

coefficient of thermal expansion, ${ }^{\circ} \mathrm{F}^{-1}$

$(\Delta t)_{c} \quad$ temperature difference across cladding, ${ }^{\circ} \mathrm{F}$ heat flux, Btu/hr-ft ${ }^{2}$

$m$ heat generated per unit length of fuel rod,

$\mathrm{W} / \mathrm{cm}$

A cross-sectional area 


\title{
PRELIMINARY PHYSICS AND HEAT TRANSFER DESIGN CALCULATIONS FOR A ROCKET FUEL TEST REACTOR (RFTR)
}

by

D. R. MacFarlane and J. T. Madell

\begin{abstract}
The concept of a test facility with which to evaluate nuclear rocket fuel elements at operating conditions was investigated. The major requirement established for such a test facility was that it produce up to a maximum power density of $10 \mathrm{MW} / \ell$ in the test section while the test reactor was limited to a power density of 2 to $2.5 \mathrm{MW} / \ell$. Calculations were performed to determine the characteristic of a test facility which would achieve the desired levels of power density. The dimensions, composition, power production, coolant flow, and fuel element size of the test reactor were among the characteristics of interest. The preliminary investigation showed that a test facility with the desired power density ratio was feasible, but that it produced large amounts of power. The results also indicated that optimization of the test reactor could reduce the total power without changing the power density ratio.
\end{abstract}

\section{INTRODUCTION}

This report will present and discuss the results of a preliminary investigation for a facility which could be utilized to test nuclear rocket fuel elements at operating conditions. The investigation was concerned with the reactor physics and heat transfer aspects of such a test facility and its test section. Criticality, flux and power distributions, and the parameters associated with heat transfer have received the greatest attention.

Test reactors have been previously employed in the development of reactor types. Fuel elements and other components of Naval reactors were and still are tested in the MTR and the ETR. FARET, when completed, will be used to evaluate fuel elements for fast power reactors. And although the Shippingport reactor and the EBWR are not test reactors as such, their operation has contributed a great deal to the pressurized and boiling water reactor programs. This success of test reactors in other reactor development programs suggested that at least a preliminary investigation should be made for a test facility for nuclear rocket fuel elements. 
The test facility considered consists of a central test section and a surrounding test reactor or a surrounding reflector. The test section refers to the region containing the rocket fuel to be tested. In most cases the test section is assumed to be surrounded by a reactor core, and the reactor core region with its reflector is called the test reactor. Only a reflector surrounds the test section in a few instances and is referred to as simply the reflector. The compositions of materials in a region are expressed as volume per cent homogenized over the region.

Three types of rocket fuel elements are currently being studied for the solid-fueled nuclear rocket concept. Due to the classified nature of this work, only one type, that proposed by ANL, was considered in this investigation. In the ANL design the rocket fuel, a cermet of $\mathrm{UO}_{2}$ and tungsten, is cooled with gaseous hydrogen. The power density in the test section is as sumed to range up to $10 \mathrm{MW} / \mathrm{l}$.

Existing test reactors operate at a maximum power density of $1 \mathrm{MW} / \mathrm{l}$ or less, but it is assumed that the next generation will operate at $2-2.5 \mathrm{MW} / \ell$ or less. The work detailed in this report was based on near-future technology, that $1 \mathrm{~s}$, on a maximum power density of $2-2.5 \mathrm{MW} / \ell$ in the test reactor.

One important problem with regard to a test facility for rocket fuel elements is operating the test at $10 \mathrm{MW} / l$ without exceeding the power density limitations in the rest of the faclity. Two approaches were tried. One consisted of surrounding a cluster of rocket fuel elements with a highly reflective, nonfissioning material. In the other approach, the test section, heavily loaded with uranium, was surrounded by a lightly loaded test reactor. Since the test section had a greater uranium concentration than the test reactor, it should also exhibit a greater power density. A third approach, the flux trap concept, was not studied in detail because it would result in large power peaks in the test section.

\section{PHYSICS CALCULATIONS}

The reactor physics analysis consisted of three sets of calculations. In the first, many types of test facilities were briefly investigated. Those facilities which held any promise of achieving the design goals were studied in more detail in the second set. From the second set, two types of test facilities were selected for a detailed parametric study, carried out in the third set of calculations. A multigroup diffusion theory code, RE-122, was used throughout the calculations with cross-section set 201 , Hansen and Roach's 16-group set(1) with cross sections for tungsten and sulfur added. Transport theory calculations were run with a DSN code for some of those cases in which diffusion theory might be expected to give significant errors; however, agreement with the RE-122 results was found to be satisfactory. 
In the preliminary calculations, the first set, the test section was assumed to have equal parts of $\mathrm{UO}_{2}$ and tungsten. Since some information about the composition of nuclear rockets is of a classified nature, the test sections discussed here are identified only by the $\mathrm{v} / \mathrm{O}$ of $\mathrm{UO}_{2}$. For the more detailed calculations, three different compositions $\left(16,22\right.$, and $30 \mathrm{v} / \mathrm{O}_{\mathrm{UO}}$ ) were employed to cover the range of possible interest. In the second set of calculations only one composition, $22 \mathrm{v} / \mathrm{o} \mathrm{UO}_{2}$, was considered; in the third set, all three compositions were considered.

\section{A. Survey Calculations in Spherical Geometry}

Initially, a series of survey problems were run in spherical geometry to find those test facilities which appeared interesting for further study. A test section with a $20-\ell$ volume and a $17-\mathrm{cm}$ radius was selected for all calculations. The compositions of those facilities are given in Table I. Basically, the approach followed in selecting the fuel for the reactor type of test facility was to select a uranium atom loading for the test reactor which was in the range of five to ten times less than that in the test section. Small quantities of moderating material were then added to soften the test reactor spectrum slightly and to reduce the critical size and fissile material inventory. Appropriate amounts of structural material and coolant, if different from the moderator, were also added. This recipe proved successful in the preliminary investigation.

Table I

TEST FACILITY COMPOSITIONS FOR CALCULATIONS IN SPHERICAL GEOMETRY

\begin{tabular}{|c|c|c|c|c|c|c|c|c|c|c|c|c|c|}
\hline \multicolumn{2}{|c|}{ Test Facility } & \multicolumn{10}{|c|}{ Composition } & \multirow{3}{*}{$\begin{array}{c}\text { Critical } \\
\text { Radius, } \\
\mathrm{cm}\end{array}$} & \multirow{3}{*}{$\begin{array}{c}\text { Max Power } \\
\text { Density } \\
\text { Ratıo }\end{array}$} \\
\hline \multirow{2}{*}{$\begin{array}{c}\text { Problem } \\
\text { No }\end{array}$} & \multirow{2}{*}{ Description } & \multicolumn{2}{|c|}{ Fuel $^{* *}$} & \multicolumn{2}{|c|}{ Moderator } & \multicolumn{2}{|c|}{ Coolant } & \multicolumn{2}{|c|}{ Structure } & \multicolumn{2}{|c|}{ Reflector } & & \\
\hline & & Materıal & v/o & Materıal & v/o & Material & v/o & Materıal & v/o & Materıal & Thickness, $\mathrm{cm}$ & & \\
\hline 103 & $\begin{array}{l}\text { Bare Test } \\
\text { Section }\end{array}$ & - & - & - & - & - & - & - & - & - & - & 389 & - \\
\hline 101 & $\begin{array}{l}\text { Ni-reflected } \\
\text { Test Section }\end{array}$ & - & - & - & - & - & - & - & - & $\mathrm{NI}$ & 100 & 237 & - \\
\hline 108 & $\begin{array}{l}\text { Be-reflected } \\
\text { Test Section }\end{array}$ & - & - & - & - & - & - & - & - & $\mathrm{Be}$ & 30 & 137 & - \\
\hline 102 & $\begin{array}{l}\text { Be-moderated } \\
\text { Reactor }\end{array}$ & $\mathrm{UO}_{2}$ & 50 & $\mathrm{Be}$ & 30.0 & $\mathrm{Na}$ & 400 & $\mathrm{Fe}$ & 250 & $\mathrm{NI}$ & 60 & 339 & 53 \\
\hline 105 & $\begin{array}{l}\text { U-Zr Fast } \\
\text { Reactor }\end{array}$ & U & 024 & - & - & $\mathrm{Na}$ & 20.0 & $\mathrm{Zr}$ & 7976 & C & 60 & 651 & 32 \\
\hline 110 & $\begin{array}{l}\mathrm{D}_{2} \mathrm{O} \text {-moderated } \\
\text { Reactor }\end{array}$ & $\mathrm{UO}_{2}$ & 49 & $\mathrm{D}_{2} \mathrm{O}$ & 667 & $\begin{array}{l}\text { Same as } \\
\text { Moderator }\end{array}$ & $\begin{array}{l}\text { Same as } \\
\text { Moderator }\end{array}$ & $\mathrm{Fe}$ & 284 & $\mathrm{Ni}$ & 60 & 269 & 41 \\
\hline 111 & $\begin{array}{l}\mathrm{H}_{2} \mathrm{O} \text {-moderated } \\
\text { Reactor }\end{array}$ & $\mathrm{UO}_{2}$ & 49 & $\mathrm{H}_{2} \mathrm{O}$ & 667 & $\begin{array}{l}\text { Same as } \\
\text { Moderator }\end{array}$ & $\begin{array}{c}\text { Same as } \\
\text { Moderator }\end{array}$ & $\mathrm{Fe}$ & 284 & $\mathrm{NI}$ & 60 & 213 & 20 \\
\hline
\end{tabular}

- The maximum power density ratio is the ratio of the peak power density in the test section to that in the test reactor

*All U is $95 \%$ enriched

The results of the survey calculations are presented in Fig. 1. Problems 102, 105, 110 , and 111 represent the use of a lightly loaded test reactor. In problems 101 and 108 the test section is surrounded with a reflector. The calculation for the bare test section (Problem 103) served as a reference. 


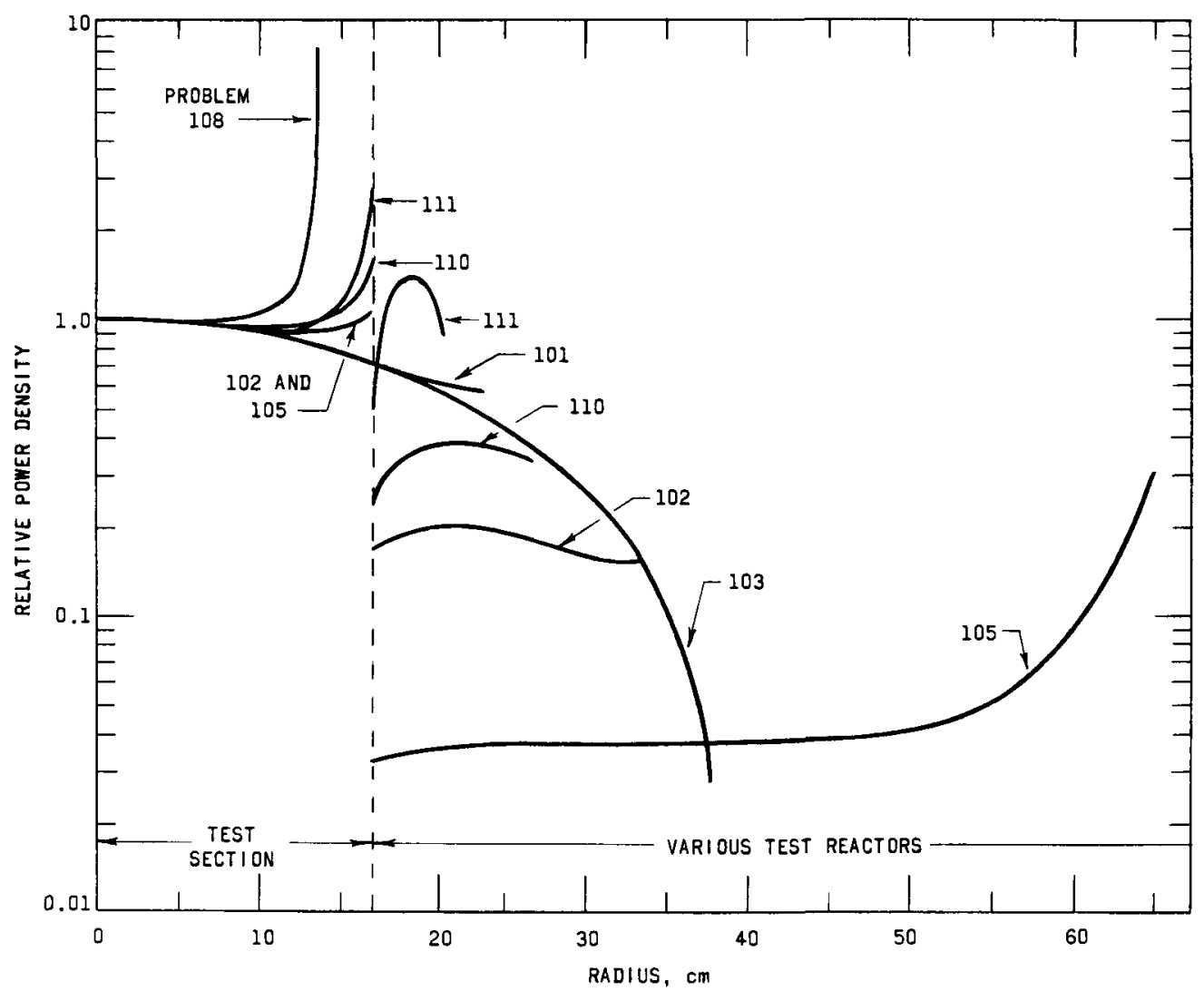

$112-3661$

Fig. 1. Relative Power Density Versus Radius for Survey Calculations. (Dimensions and compositions for the problems shown are given in Table I)

Only in the case of a beryllim-moderated test reactor (Problem 102) was the maximum power density in the test reactor below that in the test section by a factor of five.

The plots in Fig. 1 show the existence of power peaks. To determine the cause of the power peaks, the spectrum of the neutron flux was analyzed. The structure for the 16 energy groups is given in Table II. In Problems 101 , $102,103,105$, and 111 the neutron spectra were collapsed to five energy groups. The fluxes obtained are plotted in Figs. 2 through 6 . The deductions

Table II

SIXTEEN-GROUP ENERGY STRUCTURE FOR PHYSICS CALCULATIONS

\begin{tabular}{|c|c|c||c|c|c|}
\hline Group & Energy & Range & Group & Energy & Range \\
\hline 1 & $3-\infty$ & MeV & 9 & $100-550$ & eV \\
2 & $14-3$ & & 10 & $30-100$ & \\
3 & $09-14$ & & 11 & $10-30$ & $3-10$ \\
4 & $04-09$ & & 12 & $1-3$ & \\
5 & $01-04$ & & 13 & $04-1$ & \\
\hline 6 & $17-100$ & $\mathrm{keV}$ & 14 & $01-04$ & \\
7 & $3-17$ & & 15 & Thermal (0 025) & \\
\hline
\end{tabular}



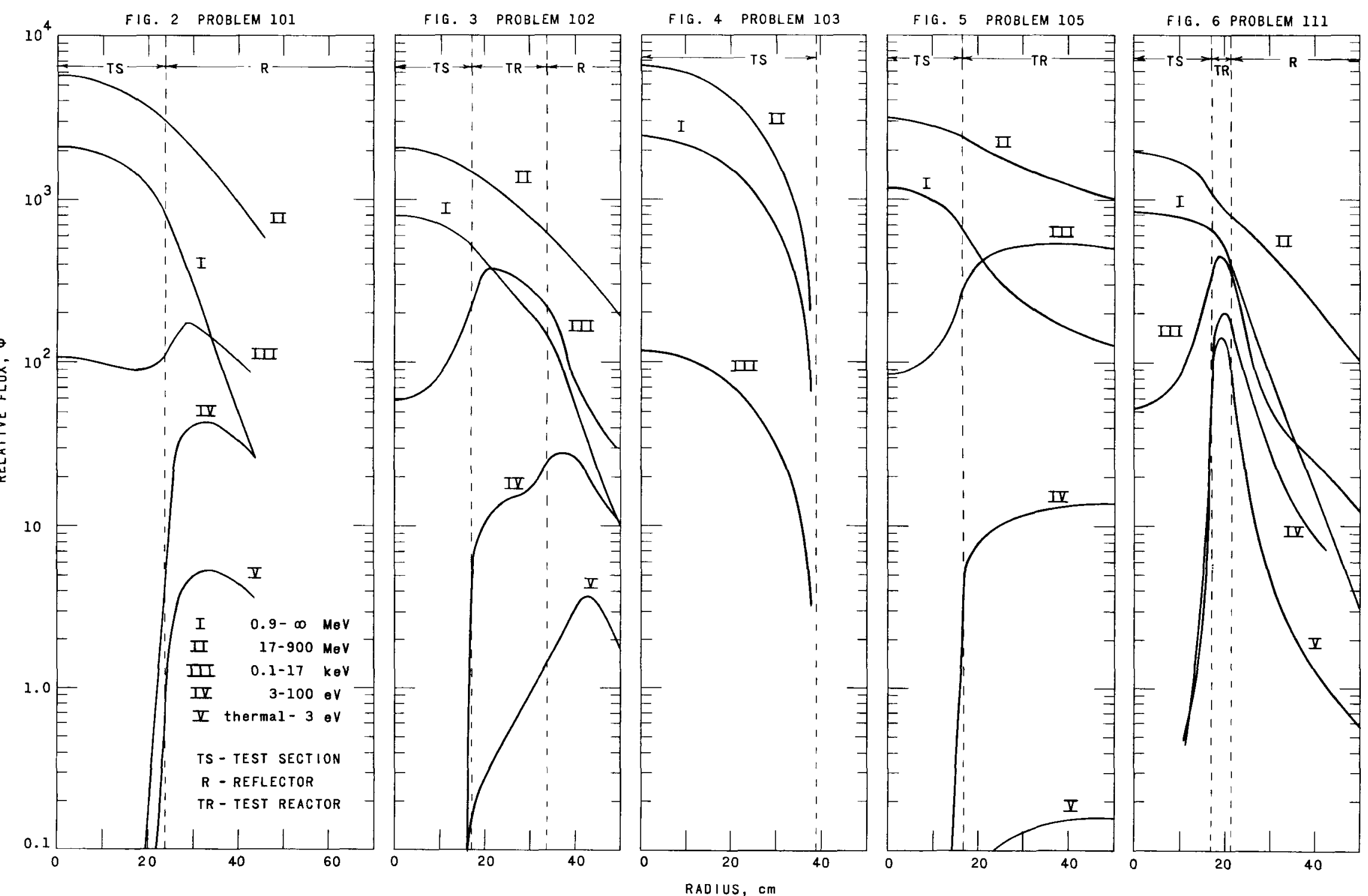

112-3991

Figs. 2-6. Relative Flux Versus Radius for Problenls $101,102,103,105$, and 111. (Dimensions and compositions for the problems shown ate given in Table I.) 
made from these figures were as follows: (1) The test section was characterized by a very hard spectrum. More than $98 \%$ of the flux had an energy greater than $17 \mathrm{keV}$ (see Fig. 4). (2) The neutron spectrum at the center of the test section was only perturbed slightly by the test reactor. At the interface between test section and test reactor the test reactor had a large influence on the neutron spectrum. Since the reactors have softer spectra than the test section, they contributed a significant number of neutrons below $17 \mathrm{keV}$ to the edge of the test section. Thus power peaks in this region were produced primarily by the softer spectrum.

As a result of the preliminary investigation of lightly loaded test reactor types, further study was given to the U-Zr (Problem 105), $\mathrm{UO}_{2}-$ beryllim oxide (Problem 102), and $\mathrm{UO}_{2}-\mathrm{D}_{2} \mathrm{O}$ (Problem 110) test reactors. No further consideration was given to $\mathrm{UO}_{2}-\mathrm{H}_{2} \mathrm{O}$ test reactor, which had a neutron spectrum inherently too soft to give the desired performance.

The power density distributions for the test section surrounded by nickel (Problem 101) and beryllium (Problem 108) are also given in Fig. 1. The effect of the moderating power of the reflector is seen by comparison of the results of Problems 108 and 101 . The beryllium reflector was more effective than the nickel reflector in reducing the critical size, but undesirable power peaks were produced. The nickel-reflected test section exhibited no power peaks, but was too large to be practical.

A set of calculations (Problems 111A, 112,113,114, and 115) were run for the $22-\mathrm{v} / 0 \mathrm{UO}_{2}$-fueled test section to determine the effect of (1) gaseous hydrogen in the test section and (2) the thickness and density of the beryllium reflector. The compositions for these calculations are given in Table III, and the results are plotted in Fig. 7. The results of Problems $111 \mathrm{~A}$ and 115 showed that hydrogen had very little influence on the critical size or power distribution; therefore, its presence could be neglected. The important result derived from Problems 112,113, and 114 was the fact that a reduction in the density and thickness of the beryllim reflector did not produce a satisfactory power density distribution. Therefore investigation of the test sections reflected with a moderating material was excluded from further study.

Table III

CONFIGURATIONS FOR CRITICAL REFLECTED TEST SECTION IN SPHERICAL GEOMETRY

\begin{tabular}{|c|c|c|c|c|}
\hline \multirow{2}{*}{$\begin{array}{c}\text { Problem } \\
\text { No. }\end{array}$} & \multirow{2}{*}{$\begin{array}{l}\text { Hydrogen in } \\
\text { Test Section }\end{array}$} & \multicolumn{2}{|c|}{ Reflector } & \multirow{2}{*}{$\begin{array}{c}\text { Critical } \\
\text { Radius } \\
\quad \mathrm{cm}\end{array}$} \\
\hline & & Material & Thickness, cm & \\
\hline $111 \mathrm{~A}$ & Present & Bare & Bare & 53.9 \\
\hline 115 & Absent & Bare & Bare & 54.4 \\
\hline 113 & Present & $\mathrm{Be}$ of $70 \%$ density & 20 & 31.7 \\
\hline 112 & Present & Be of full density & 20 & 23.4 \\
\hline 114 & Present & Be of full density & 40 & 17.6 \\
\hline
\end{tabular}




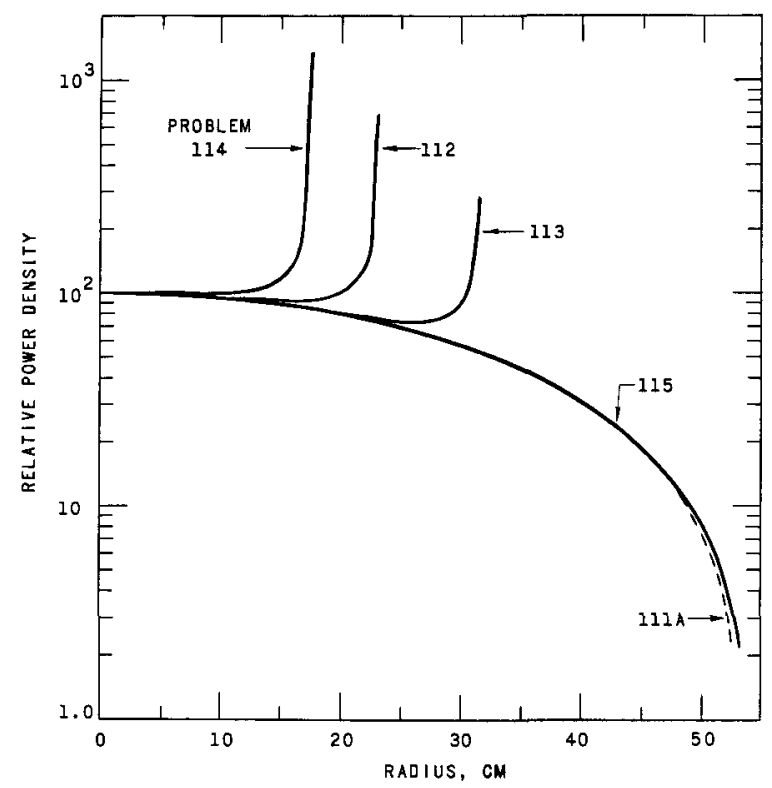

Fig. 7

Relative Power Density Versus Radius for Problems $111 \mathrm{~A}, 112$, 113, 114, and 115. (Dimensions and compositions for the problems shown are given in Table III.)

$112-3988$

B. Calculations in Infinite Cylindrical Geometry

The effect of fuel concentration in the test reactor on the power density ratio and the ratio of the power in the test section to that in the test reactor were of particular interest in the second set of calculations. The three reactor-type test facilities which appeared interesting from the results of the calculations in spherical geometry, namely, the $\mathrm{D}_{2} \mathrm{O}$-moderated epithermal test reactor (Problem 110), the Be-moderated epithermal test reactor (Problem 102), and the U-Zr-fueled fast center zone surrounded by a graphite-moderated thermal test reactor (Problem 105), were studied further using infinite cylindrical geometry. Since it was apparent that the use of the moderating reflector resulted in undesirable power peaks at the outer edge of the test reactor, in all of the subsequent work in cylindrical geometry a nonmoderating reflector, usually nickel, was used.

\section{Selection of Test Section for All Calculations in Infinite Cylindrical Geometry}

Throughout the calculations in infinite cylindrical geometry the test section was assumed to be a cylinder roughly $13 \mathrm{~cm}$ in radius. In an effort to be more realistic by providing protection for both the test section and the test reactor, a 1 -cm-thick cylindrical vessel containing tungsten was interposed between the test section and the test reactor in all these calculations.

\section{Beryllium-moderated Epithermal-type Test Reactors}

Criticality calculations were performed for four core compositions of the Be-moderated test reactors. The composition, critical radius, 
and maximum power density ratio for each of the four test reactors (Problems 119, 121, 123, and 131) are presented in Table IV.

Table II

TEST REACTOR COMPOSITIONS FOR INFINITE CYLINDER CALCULATIONS WITH A 22-V/O U02 TEST SECTION

\begin{tabular}{|c|c|c|c|c|c|c|c|c|c|c|c|c|c|}
\hline \multicolumn{2}{|c|}{ Test Reactor } & \multicolumn{10}{|c|}{ Composition } & \multirow{3}{*}{$\begin{array}{c}\text { Critical } \\
\text { Radius, } \\
\text { cm }\end{array}$} & \multirow{3}{*}{$\begin{array}{c}\text { Max Power } \\
\text { Density } \\
\text { Ratio }\end{array}$} \\
\hline \multirow{2}{*}{$\begin{array}{l}\text { Problem } \\
\text { No }\end{array}$} & \multirow{2}{*}{ Description } & \multicolumn{2}{|c|}{ Fue $\left.\right|^{*}$} & \multicolumn{2}{|c|}{ Moderator } & \multicolumn{2}{|c|}{ Coolant } & \multicolumn{2}{|c|}{ Structure } & \multicolumn{2}{|c|}{ Reflector } & & \\
\hline & & Materıal & v/o & Materıal & v/o & Materıal & v/o & Materıal & v/o & Materıal & Thıckness, cm & & \\
\hline 119 & $\begin{array}{l}\text { Be-moderated } \\
\text { Reactor }\end{array}$ & $\mathrm{UO}_{2}$ & 50 & $\mathrm{Be}$ & 300 & $\mathrm{Na}$ & 400 & $\mathrm{Fe}$ & 250 & $\mathrm{NI}$ & 30 & 286 & 28 \\
\hline 121 & $\begin{array}{l}\text { Be-moderated } \\
\text { Reactor }\end{array}$ & $\mathrm{UO}_{2}$ & 25 & $\mathrm{Be}$ & 300 & $\mathrm{Na}$ & 400 & $\mathrm{Fe}$ & 275 & $\mathrm{NI}$ & 30 & 352 & 38 \\
\hline 123 & $\begin{array}{l}\text { Be-moderated } \\
\text { Reactor }\end{array}$ & $\mathrm{UO}_{2}$ & 125 & $\mathrm{Be}$ & 300 & $\mathrm{Na}$ & 400 & $\mathrm{Fe}$ & 2875 & $\mathrm{Ni}$ & 30 & 451 & 48 \\
\hline 131 & $\begin{array}{l}\text { Be-moderated } \\
\text { Reactor }\end{array}$ & $\mathrm{UO}_{2}$ & 125 & $\mathrm{Be}$ & 76 & $\mathrm{Na}$ & 400 & $\mathrm{Fe}$ & 511 & $\mathrm{~N}$ & 30 & 727 & 76 \\
\hline 125 & $\begin{array}{l}\mathrm{D}_{2} \mathrm{O} \text {-moderated } \\
\text { Reactor }\end{array}$ & $\mathrm{U} 02$ & 49 & $\mathrm{D}_{2} \mathrm{O}$ & 667 & $\begin{array}{l}\text { Same as } \\
\text { Moderator }\end{array}$ & $\begin{array}{l}\text { Same as } \\
\text { Moderator }\end{array}$ & $\mathrm{Fe}$ & 284 & $\mathrm{No}$ & 30 & 263 & 16 \\
\hline 127 & $\begin{array}{l}\mathrm{D}_{2} \mathrm{O} \text {-moderated } \\
\text { Reactor }\end{array}$ & $\mathrm{UO}_{2}$ & 245 & $\mathrm{D}_{2} 0$ & 667 & $\begin{array}{l}\text { Same as } \\
\text { Moderator }\end{array}$ & $\begin{array}{l}\text { Same as } \\
\text { Moderator }\end{array}$ & $\mathrm{Fe}$ & 309 & $\mathrm{NI}$ & 30 & 319 & 21 \\
\hline 129 & $\begin{array}{l}\text { D20-moderated } \\
\text { Reactor }\end{array}$ & $\mathrm{UO}_{2}$ & 245 & $\mathrm{D}_{2} \mathrm{O}$ & 400 & $\begin{array}{l}\text { Same as } \\
\text { Moderator }\end{array}$ & $\begin{array}{l}\text { Same as } \\
\text { Moderator }\end{array}$ & $\mathrm{Fe}$ & 575 & $\mathrm{NI}$ & 30 & 372 & 26 \\
\hline 240 & $\begin{array}{l}\text { U-Zr Fast } \\
\text { Reactor }\end{array}$ & $u$ & 10 & - & - & $\mathrm{Na}$ & 250 & $\mathrm{Zr}$ & 740 & $\mathrm{Ni}$ & 30 & 857 & 89 \\
\hline 242 & $\begin{array}{l}U-Z r \text { Fast } \\
\text { Reactor }\end{array}$ & $\mathrm{u}$ & 20 & - & - & $\mathrm{Na}$ & 250 & $\mathrm{Zr}$ & 730 & $\mathrm{No}$ & 30 & 525 & 54 \\
\hline 244 & $\begin{array}{l}\text { U-Zr Fast } \\
\text { Reactor }\end{array}$ & U & 30 & - & - & $\mathrm{Na}$ & 250 & $\mathrm{Zr}$ & 720 & $\mathrm{NI}$ & 30 & 407 & 38 \\
\hline 250 & $\begin{array}{l}\text { U-Zr Fast } \\
\text { Reactor }\end{array}$ & U & 10 & - & - & $\mathrm{Na}$ & 350 & $\mathrm{Zr}$ & 640 & $\mathrm{NI}$ & 30 & 815 & 88 \\
\hline 252 & $\begin{array}{l}\text { U-Zr Fast } \\
\text { Reactor }\end{array}$ & U & 20 & - & - & $\mathrm{Na}$ & 350 & $\mathrm{Zr}$ & 630 & $\mathrm{Ni}$ & 30 & 517 & 54 \\
\hline 254 & $\begin{array}{l}\text { U-Zr Fast } \\
\text { Reactor }\end{array}$ & U & 30 & - & - & $\mathrm{Na}$ & 350 & $\mathrm{Zr}$ & 620 & $\mathrm{NI}$ & 30 & 405 & 38 \\
\hline
\end{tabular}

*All $U$ is $95 \%$ enriched

In Problems 119, 121, and 123, the fuel composition for each test reactor was increased at the expense of the structural material (iron). The $\mathrm{UO}_{2} / \mathrm{Be}$ ratio $1 \mathrm{~s}$ therefore different in these three problems. In Problem 131 , the $\mathrm{UO}_{2} / \mathrm{Be}$ ratio was made almost the same as in Problem 119. The volume fraction of sodium for all four problems was 0.40 .

The power density distribution curves for all four of the beryllium-moderated test reactors are plotted in Fig. 8, and the flux spectrum plots for Problems 119 and 123 are shown in Figs. 9 and 10, respectively. From Figs. 9 and 10 it can be seen that increasing the uranium concentration (1) lowered the maximum power density ratio, (2) reduced the size and also the power output of the particular test reactor, and (3) hardened the neutron spectrum. Decreasing the beryllium concentration (Problem 131) hardened the spectrum which, in turn, increased the power density ratio and the size of the test reactor. 


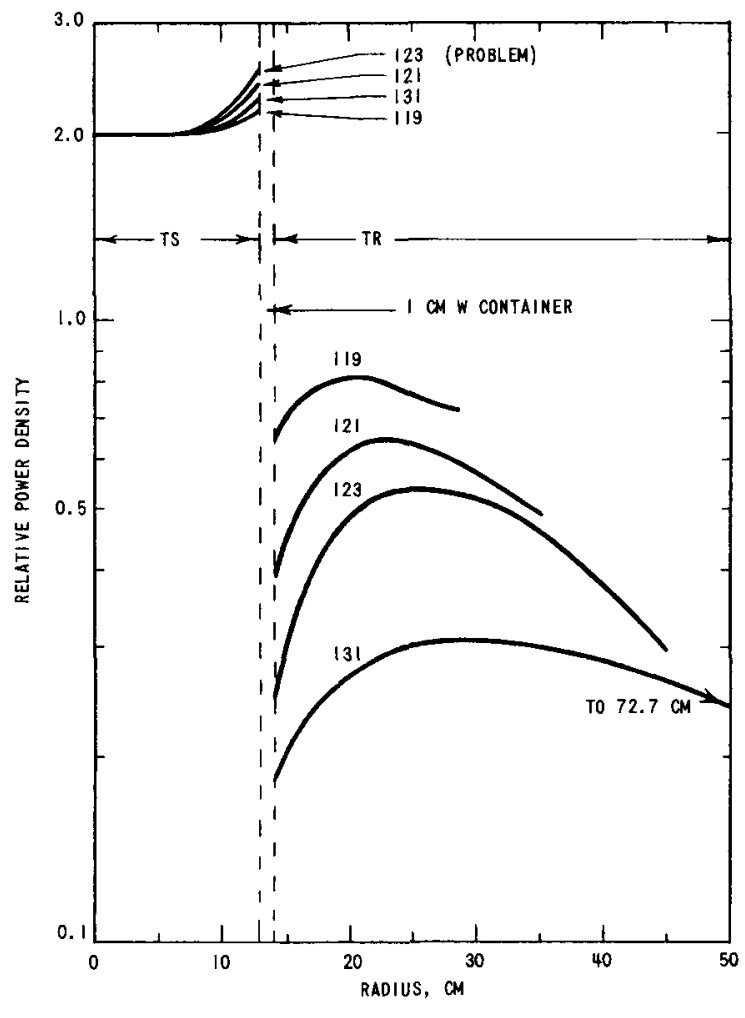

$112-4010$

Fig. 8. Relative Power Density Versus Radius for Beryllium-moderated Test Reactors (Problems 119, 121, 123, and 131). (Dimensions and compositions for the problems shown are given in Table IV.)
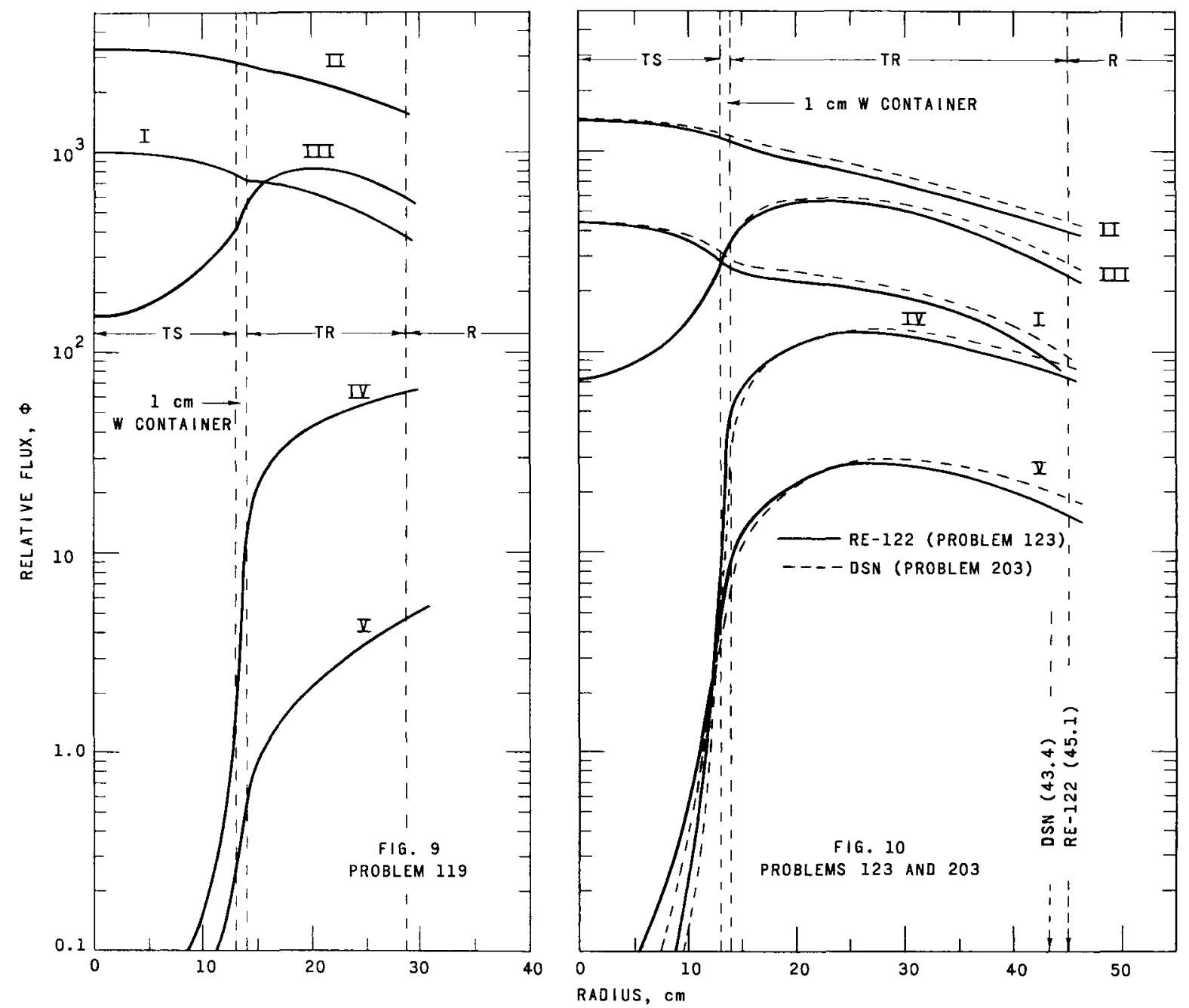

$112-3990$

Figs. 9-10. Relative Flux Versus Radius for Beryllium-moderated Test Reactors (Problems 119, 123, and 203). (Dimensions and compositions for the problems shown are given in Table IV. See legend in Fig. 2 for energy-group designations.) 
To check the validity of the diffusion theory calculations in these reactors, corresponding problems were run for some of the cases with cross-section set 201 and the DSN transport theory code. A comparison for Problem 123 is presented in Fig. 10. As can be seen from the figure, the agreement between the diffusion theory and transport theory calculations is reasonably good and is certainly close enough so that results by diffusion theory can be relied upon for the purposes of this study.

\section{Heavy Water-moderated Epithermal-type Test Reactors}

The configuration used for the heavy water-moderated test reactors was a fully enriched $\mathrm{UO}_{2}$ fuel, clad with iron, and cooled and moderated with heavy water. The three compositions (Problems 125, 127, and 129) for these reactors are given in Table IV, and the calculated power distributions are given in Fig. 11. Plots of the neutron spectrum for two of these test reactors (Problems 125 and 127) are presented in Figs. 12 and 13, respectively. It can be seen that the effects of changing the uranium and moderator concentrations in the $\mathrm{D}_{2} \mathrm{O}$ systems were qualitatively the same as those observed in the beryllium-moderated systems.

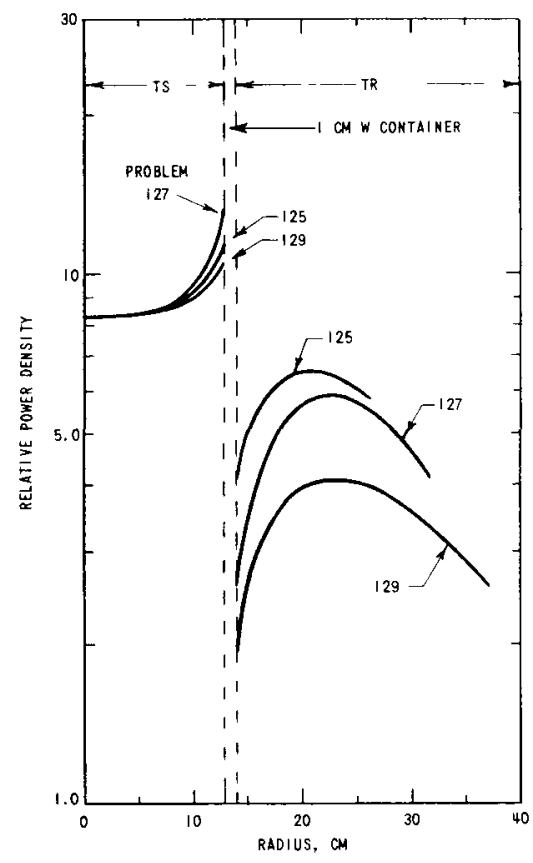

Fig. 11

Relative Power Density Versus Radius for $\mathrm{D}_{2} \mathrm{O}$-moderated Test Reactors (Problems 125, 127, and 129). (Dimensions and compositions for the problems shown are given in Table IV.)

$112-4007$

The highest value of the maximum power density ratios for these three cases was 2.6 (in Problem 129) which was well below the desired value of 4 or 5 . It should be noted that the test reactor in this problem contained the least amount of heavy water of the three reactors and therefore possessed the hardest spectrum. Reducing the volume fraction of $\mathrm{D}_{2} \mathrm{O}$ below a value of 0.40 also reduced the capability of the reactor for heat removal. Therefore, it does not seem likely that a power density ratio of 4 or 5 could be obtained with a practical design of a heavy water test reactor. 


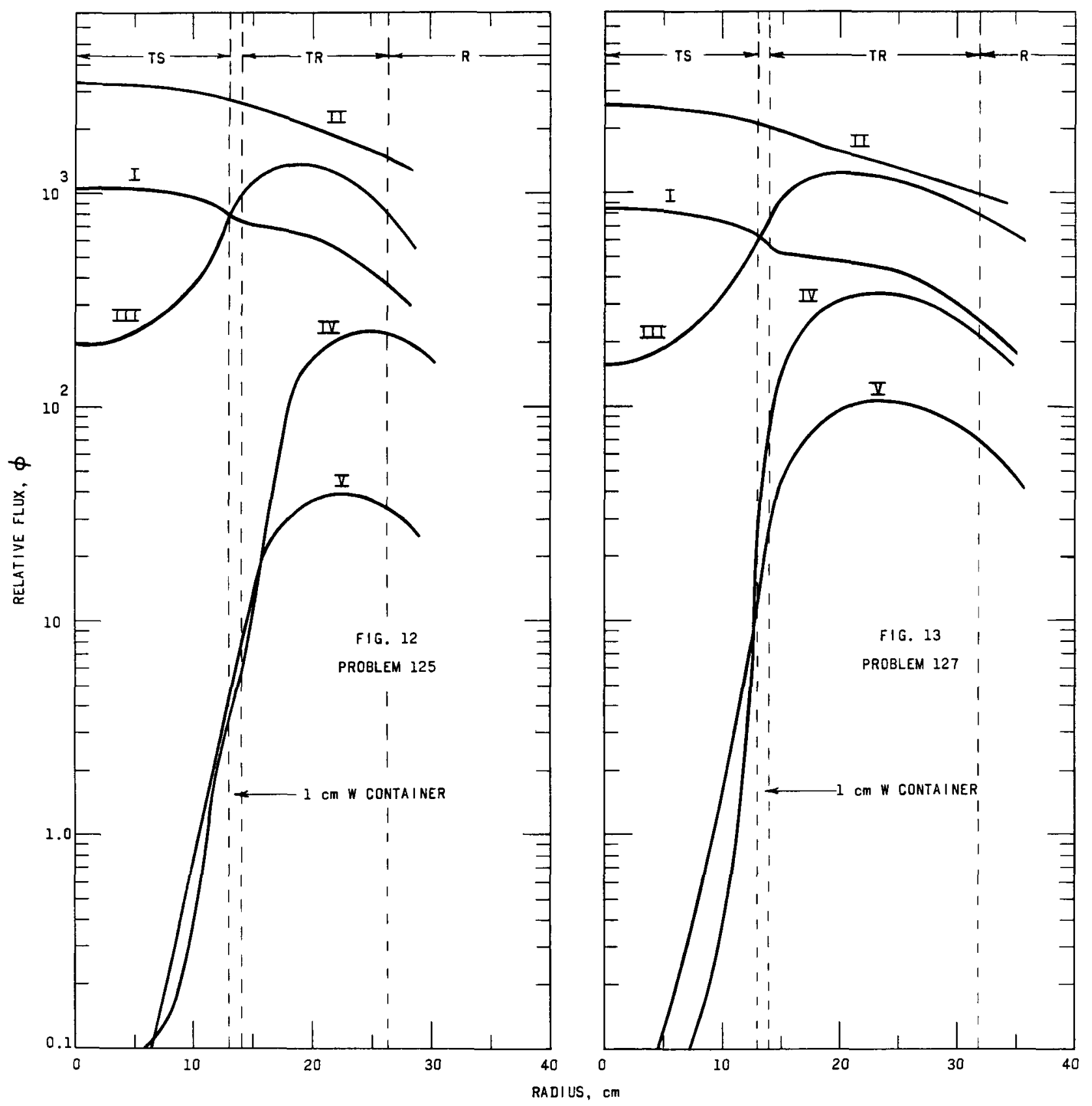

$112-4006$

Figs. 12-13. Relative Flux Versus Radius for $\mathrm{D}_{2} \mathrm{O}$-moderated Test Reactors (Problems 125 and 127). (Dimensions and compositions for the problems shown are given in Table IV. See legend in Fig. 2 for energy-group designations.)

4. Uranium-Zirconium-alloy-fueled Fast Reactors

The third type of test reactor considered in this set of calculations was the uranium-zirconium-fueled, sodium-cooled fast reactor. 
Nickel was used as a nonmoderating reflector for reasons mentioned previously. Three values of the uranium concentrations and two values of the sodium volume fraction were used in the criticality calculations for six test reactors (Problems 240, 242, 244, 250, 252, and 254). The composition of each of the six reactors is given in Table IV. The results of the power distribution calculations are plotted in Figs. 14 and 15. The neutron spectrum plots for Problems 242 and 252, given in Figs. 16 and 17, respectively, show that the U-Zr-Na reactors were characterized by a neutron spectrum that was almost as fast as the test section. The flat power distributions in the test section and test reactor, as well as the large critical radius of the test reactor, were expected for a reactor with such a neutron spectrum. Again, the power density ratio and the critical size decreased with an increased uranium concentration.

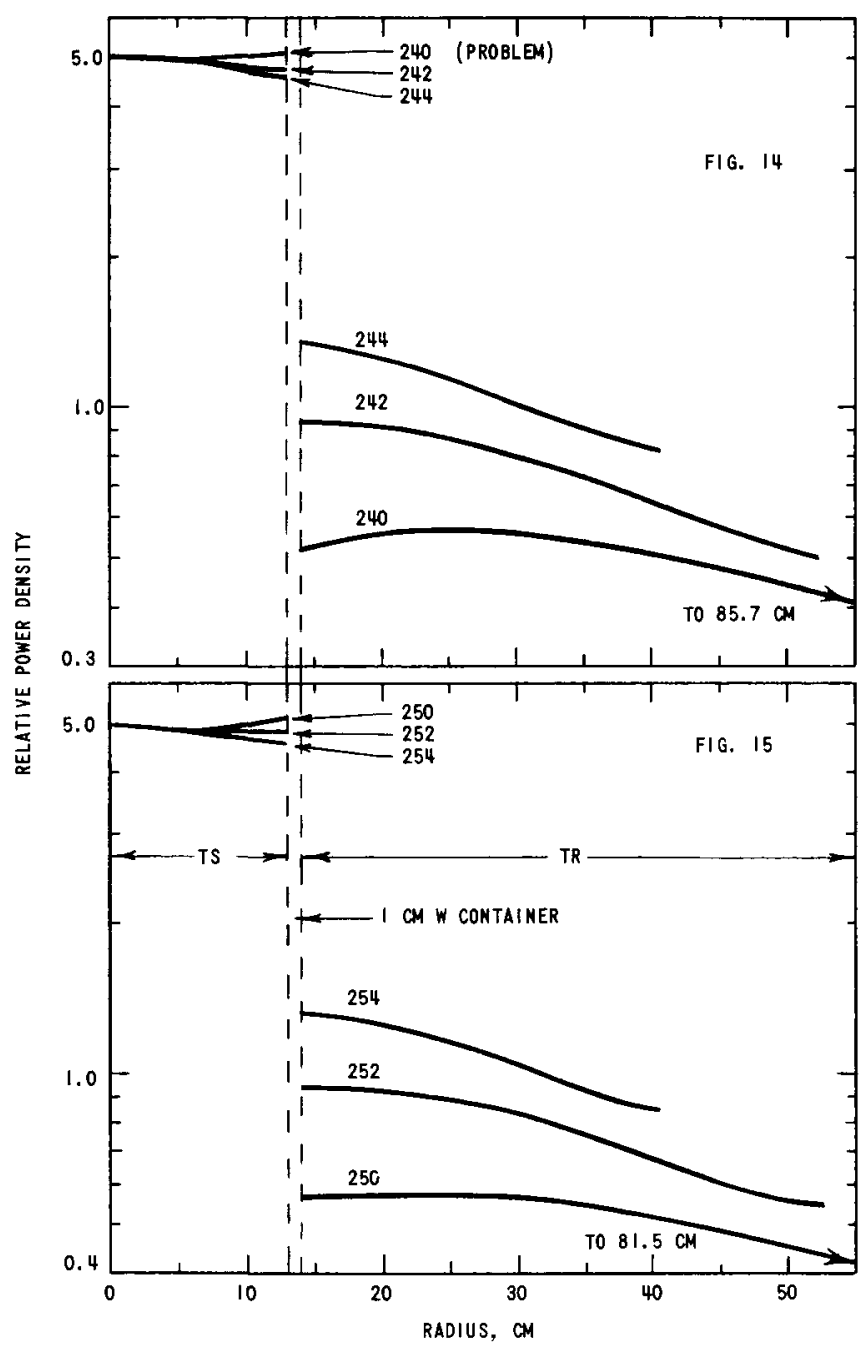

$112-4009$

Figs. 14-15. Relative Power Density Versus Radius for Uranıum-Zirconıum Fast Reactors with $25 \%$ and $35 \%$ Sodıum. (Dimensions and compositions for the problems shown are given in Table IV.) 


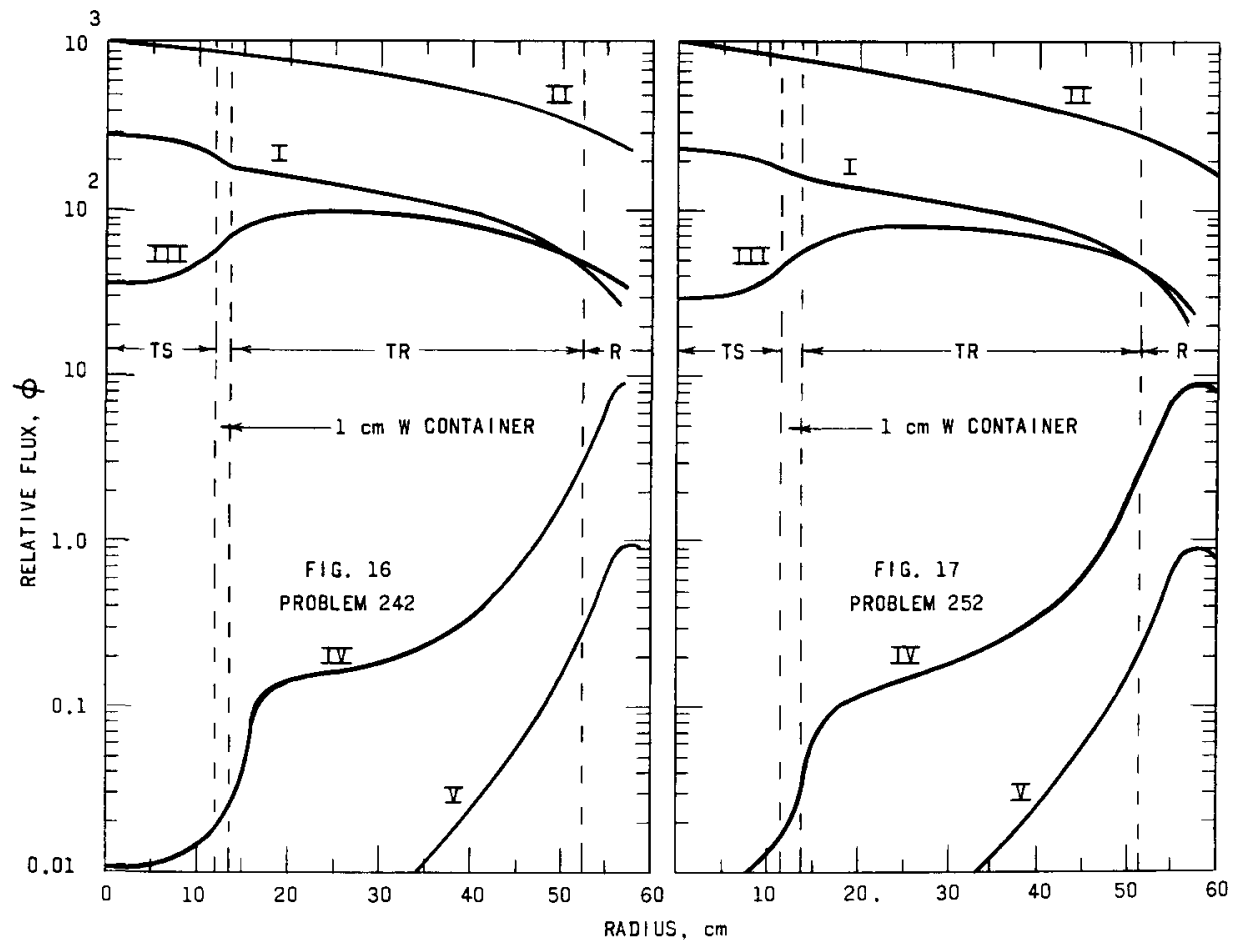

$112-4003$

Figs. 16-17. Relative Flux Versus Radius for UraniumZirconium Fast Reactors (Problems 242 and 252). (Dimensions and compositions for the problems shown are given in Table IV. See legend in Fig. 2 for energygroup designation.)

5. Comparison of Infinite Cylindrical Calculations for Various Systems

As stated, the objective of these parametric studies was to select a test reactor or reactors which gave a large (4 or greater) power density ratio between the test section and the test reactor. By comparing the results in Table IV, it can be seen that the $\mathrm{D}_{2} \mathrm{O}$ test reactors having a minimum volume fraction of $\mathrm{D}_{2} \mathrm{O}$ that would be suitable for cooling purposes (Problem 129) also had a smaller power density ratio than the other two types of test reactors. These factors discouraged further study of the $\mathrm{D}_{2} \mathrm{O}$-moderated reactors.

Summaries of the results of the calculations for the berylliummoderated epithermal and uranium-zirconium fast reactors are given in Figs. 18 and 19. As shown by Fig. 18, the maximum power density ratio versus total power ratio curves for the two systems are quite similar. In regards to the power ratio, the uranium-zirconium reactors evidenced a slight advantage at the larger power density ratios, whereas the berylliummoderated reactors showed an advantage at the lower values of the power density ratio. 


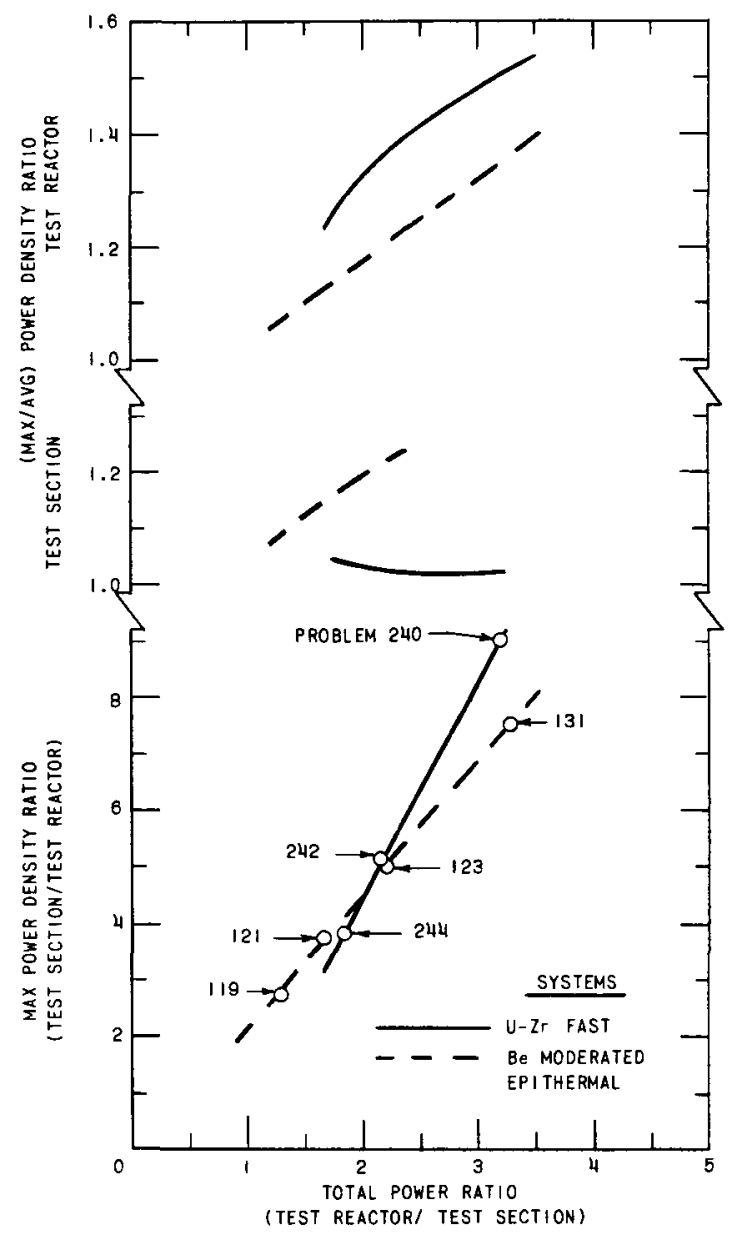

$112-3995$

Fig. 18. Power Density Ratios Versus Total Power Ratio for the Beryllium moderated and Uranium Zirconium Fast Test Reactors

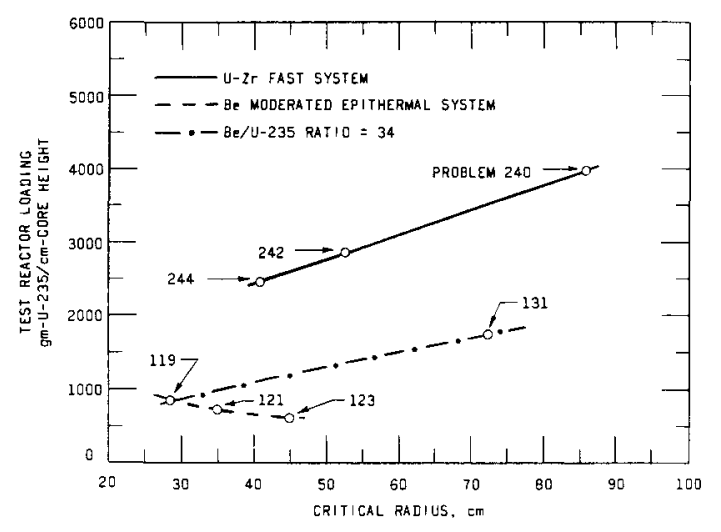

$112-3994$

Fig. 19. Test Reactor Loading Versus Critical Radius for the Beryllium-moderated and the Uranium-Zirconium Fast Test Reactors
The fact that the power output of both test reactors was quite sizable is an important consideration. In terms of the beryllium-moderated test reactor, the results in Fig. 18 can be illustrated by the following example. Let the test section have a volume of $30 \mathrm{l}$ and a peak power density of $10 \mathrm{MW} / \ell$. If radial and axial max/avg power ratios of 1.1 and 1.2 , respectively, can be as sumed, the average power density in the test section is calculated to be $7.6 \mathrm{MW} / \ell$ and the total test section power is $228 \mathrm{MW}$. The use of 3 for the maximum total power ratio and of 7.0 for the maximum power density ratio (from the figure) results in a test reactor power of $684 \mathrm{MW}$ and a maximum power density in the test reactor of $10 / 7$ or about $1.4 \mathrm{MW} / \mathrm{l}$.

Another factor in the design of a test reactor is the required fuel loadings shown in Fig. 19. It should be noted that the beryllium-moderated and uranium-zirconium fast test reactors which gave the largest power density ratios (Problems 131 and 240 , respectively) also produced the largest power and required the largest fuel loadings. (It is clear that compromises in the parameters of the test reactor selected will be in order.)

The values of the power and the fuel loadings obtained from the infinite cylindrical calculations are given for a unit height of the test reactor. Calculations for a finite cylindrical test assembly were performed to obtain the absolute values for these quantities.

C. Calculations in Finite Cylindrical Geometry

All previous calculations were one-dimensional, that is, the geometries have been either spherical or infinite 
cylindrical. A finite cylinder, which would be the shape of an actual test reactor, would have different nuclear properties than an infinite cylinder. The finite height of a reactor may be taken into account by either doing a two-dimensional criticality calculation or by adjusting a one-dimensional calculation to take into account the influence of a finite height. The latter procedure was used because of the preliminary nature of the work.

The general physical arrangement of the nuclear rocket test reactor is shown in Fig. 20. The test section is reflected at top and bottom. The test reactor itself is also reflected at top and bottom and on the outer edges.

To calculate criticality by a one-dimensional code, the equivalent height of a bare test section and reactor core must be known. In Fig. 21 , the computational model of the reactor is shown with the axial reflectors removed, and with the new heights of the test section and reactor core expressed as equivalent heights. With such a computational model, a onedimensional code, RE-122, can be used to calculate the criticality and radial power and flux distributions. The equivalent heights of each of the test sections (for 16,22 , and $30 \mathrm{v} / \mathrm{OUO}_{2}$ ) and the reactor core were approximated by a set of two calculations. This set of two calculations will be demonstrated for a test section and the same procedure applies to the reactor core.

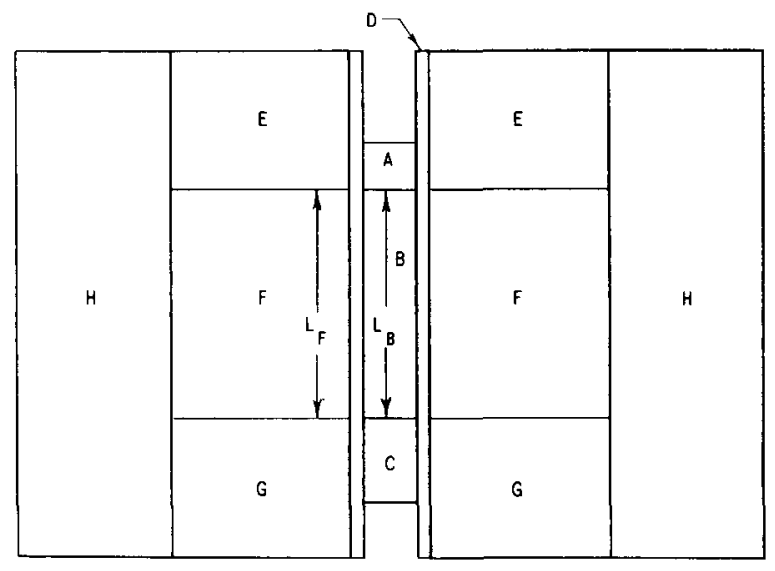

\footnotetext{
A - TOP TEST REFLECTOR

B - ACTIVE TEST CORE

C - BOTTOM TEST REFLECTOR

D - TEST SECTION LINER

$L_{B}$ AND $L_{F}-A C T$ IVE HEIGHT OF TEST AND REACTOR CORES
}

\section{$112-3998$}

Fig. 20. Vertical Section of the Test Section, Test Reactor and Reflector.

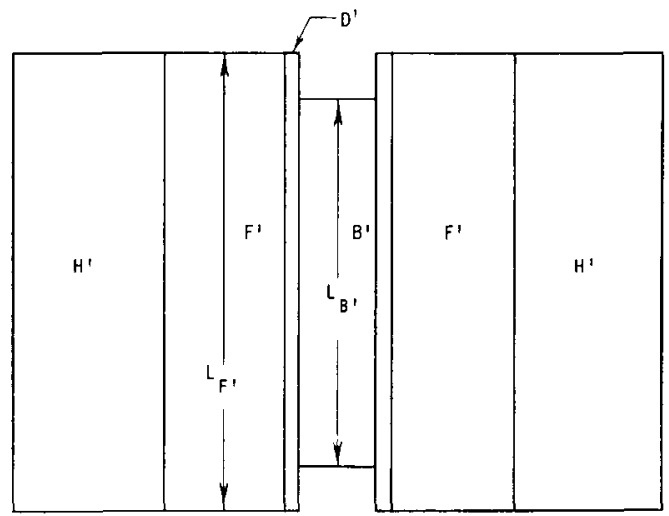

B' - EOUIVALENT BARE (AXIALLY) TEST SECTION

D' - TEST SECTION LINER

F' - EQU I VALENT BARE (AXIALLY) REACTOR

$H^{\prime}$ - RADIAL REFLECTOR

$L_{B^{\prime}}$ - EQUIVALENT HEIGHT OF TEST SECTION

$L_{F^{\prime}}$ - EQUIVALENT HEIGHT OF REACTOR

$112-3997$

Fig. 21. Computational Model of the Test Section, Test Reactor, and Radial Reflector. 
Figure $22 \mathrm{a}$ shows the test section with reflectors at both ends. A one-dimensional calculation was used to determine the required radial buckling to achieve criticality for the system. The value of the radial buckling was then transformed into a

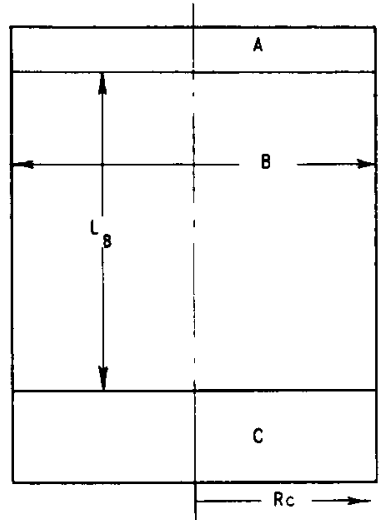

(a)

A - TOP REFLECTOR

8 - TEST SECTION

C - BOTTOM REFLECTOR

B'- EQUIVALENT BARE (AXIALLY) TEST SECTION

$112-4002$

Fig. 22. Models of Test Section for Computing the Equivalent Height

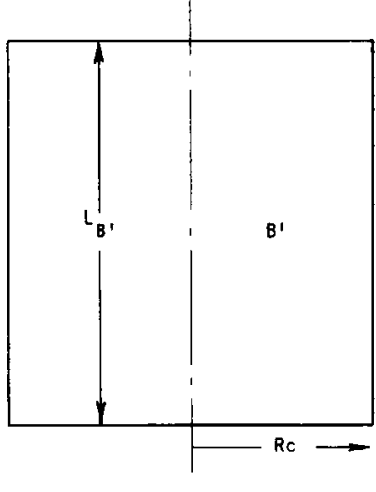

(b)

$L_{B}$ - HEIGHT OF TEST SECTION

$L_{B}$ - EQUIVALENT HEIGHT OF

RC- CRITICAL RADIUS critical radius. By means of the calculated value for the critical radius, the height of a bare test section (one with no axial or radial reflectors) was calculated with a one-dimensional code (see Fig. 22b). The critical height then is said to be equal to the equivalent height of the axially reflected test section. These calculations were accurate within the limitations of the computer code as long as the test section is not surrounded by the reactor. However, when the test section is placed within the reactor the nuclear properties of the test section are perturbed by the reactor, and the perturbations in turn influence the equivalent height.

In the cases considered in this study, the neutron spectrum of the test section and reactor were similar. The perturbation was, therefore, not large, and it is believed that this method provides a fairly accurate and quick means of determining the equivalent height. The equivalent heights of various test sections and the two remaining test reactors [(1) a fast, sodium-cooled reactor fueled with a dilute mixture of uranium in zirconium, and (2) a sodium-cooled, uranium oxide-beryllium oxide-fueled reactor] are presented in Table $V$. The axial power distribution plots for a test section $\left(22 \mathrm{v} / \mathrm{O} \mathrm{UO}_{2}\right)$ and the two types of test reactors are shown in Figs. 23, 24, and 25. In addition, criticality calculations were performed in finite cylindrical geometry for a test section with a nonmoderating reflector.

\section{Table V}

EQUIVALENT HEIGHTS OF TEST SECTION AND TEST REACTOR

\begin{tabular}{|c|c|c|c|}
\hline $\begin{array}{c}\mathrm{UO}_{2} \text { Composition, } \\
\text { v/o }\end{array}$ & $\begin{array}{r}\text { Equivalent Height, } \\
\mathrm{cm}\end{array}$ & \multicolumn{1}{|c|}{ Type } & $\begin{array}{c}\text { Equivalent Height, } \\
\mathrm{cm}\end{array}$ \\
\hline \multicolumn{2}{|c|}{ Test Sections } & \multicolumn{2}{|c|}{ Test Reactors } \\
\hline 16 & 97.54 & $\mathrm{UO}_{2}-\mathrm{BeO}_{2}-\mathrm{Na}-\mathrm{Fe}$ & 109.32 \\
22 & 100.77 & $\mathrm{U}-\mathrm{Zr}-\mathrm{Na}$ & 122.29 \\
30 & 96.67 & & \\
\hline
\end{tabular}



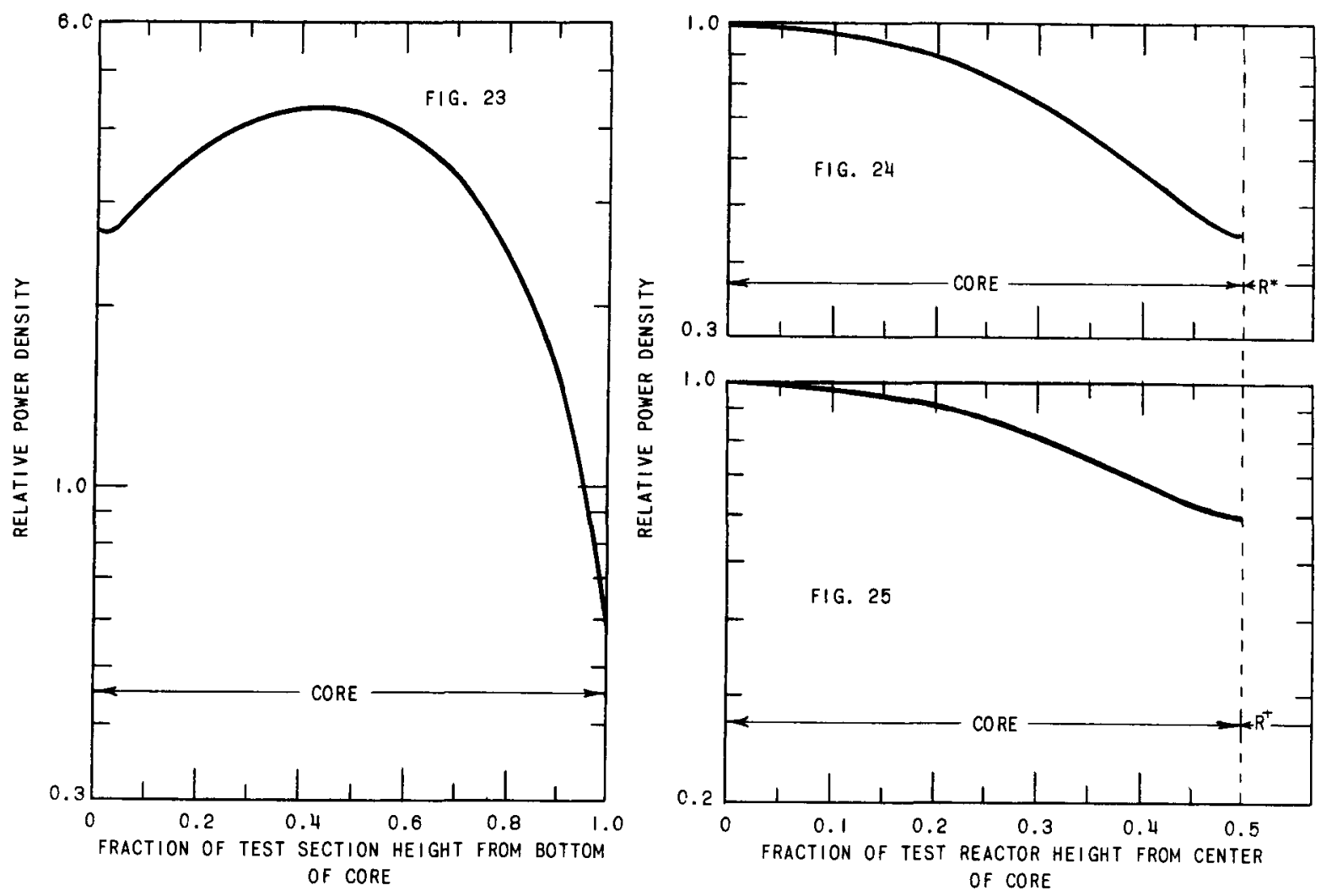

* $60 \mathrm{~cm} \mathrm{~N}$ I REFLECTOR WITH $40 \% \mathrm{Na}$

$+60 \mathrm{~cm} \mathrm{~N}$ I REFLECTOR WITH $25 \% \mathrm{Na}$

\section{$112-3987$}

Figs. 23-25. Axial Power Density for Test Section, Beryllium-moderated Test Reactor and Uranium-Zirconium Fast Test Reactor. (The test section and test reactors have representative compositions.)

\section{Criticality Calculations for Reactors with Test Section}

The parameters investigated for the two remaining types of reactors were (a) fuel loading in the reactor, (b) radial dimension of a test section, and (c) $\mathrm{UO}_{2}$ loading in the test section. The most important results from the computer program were the power density distribution in both test section and reactor, the power generated in the test reactor, and the neutron spectrum within the test section and reactor core.

\section{(a) Fuel Loading of the Reactor}

Uranium loading in the two types of reactors was varied for different sizes and loadings of the test section. Uranium loadings of 3 and $5 \mathrm{v} / 0$ in the dilute fast reactor and $\mathrm{UO}_{2}$ loadings of $1.25,2.5$, and

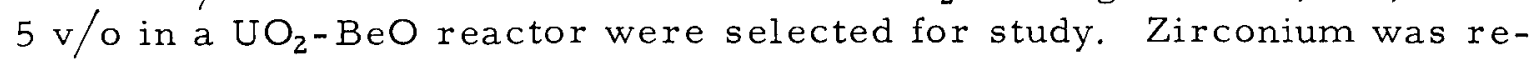
moved as the uranium was added in the fast dilute reactor, and beryllium oxide was removed as the uranium content was increased in the other reactor. 
(b) Size of the Test Section

Calculations for test sections of 3-, 6-, 9-, and $13-\mathrm{cm}$ radii were performed for both types of reactors and for all loadings of both the reactor and the test section. The equivalent bare heights used in each region are given in Table $\mathrm{V}$. The test sections were surrounded by a $1-\mathrm{cm}-$ thick annular tungsten container.

\section{(c) Fuel Loading of the Test Section}

A range of $\mathrm{UO}_{2}$ loadings $(16,22$, and $30 \mathrm{v} / \mathrm{o})$ in the test section was studied. The composition of the other components is not specified.

Both types of reactors under study were reflected at top and bottom with $60 \mathrm{~cm}$ of nickel. A $30-\mathrm{cm}$, nickel radial reflector was used in all cases. The volume fraction of sodium was usually $50 \%$ for both types of reactors.

The relative radial distribution of power density, which is part of the computer output, was plotted for each combination of parameters. Eight of the plots appear in Figs. 26 through 33. The calculations for power

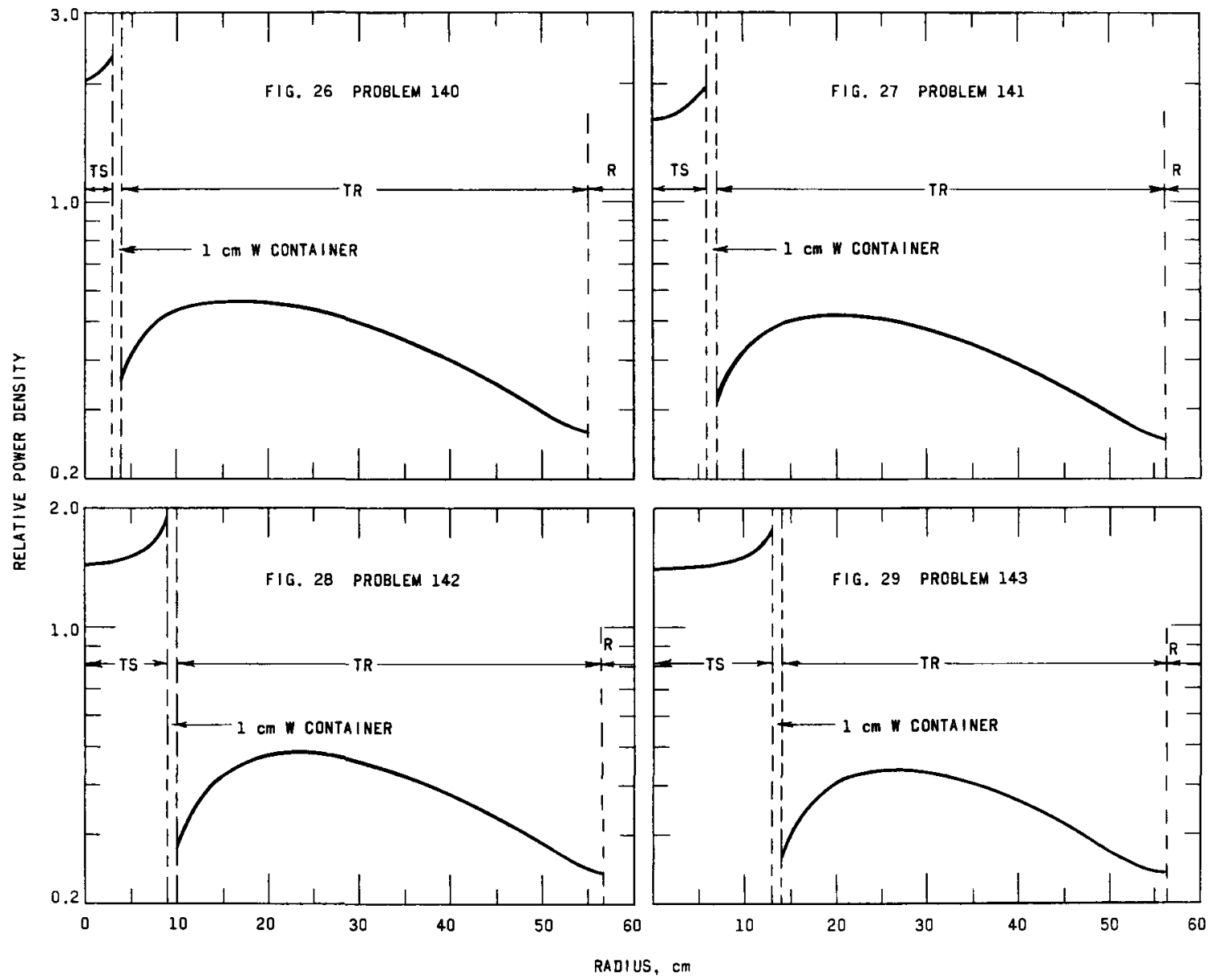

$112-4005$

Figs. 26-29. Relative Power Density Versus Radius for Beryllium-moderated Test Reactors with 3-, 6-, $9-$, and 13-cm-radius Test Sections (TS). (Dimensions and compositions for the problems shown are given in Table VII.) 


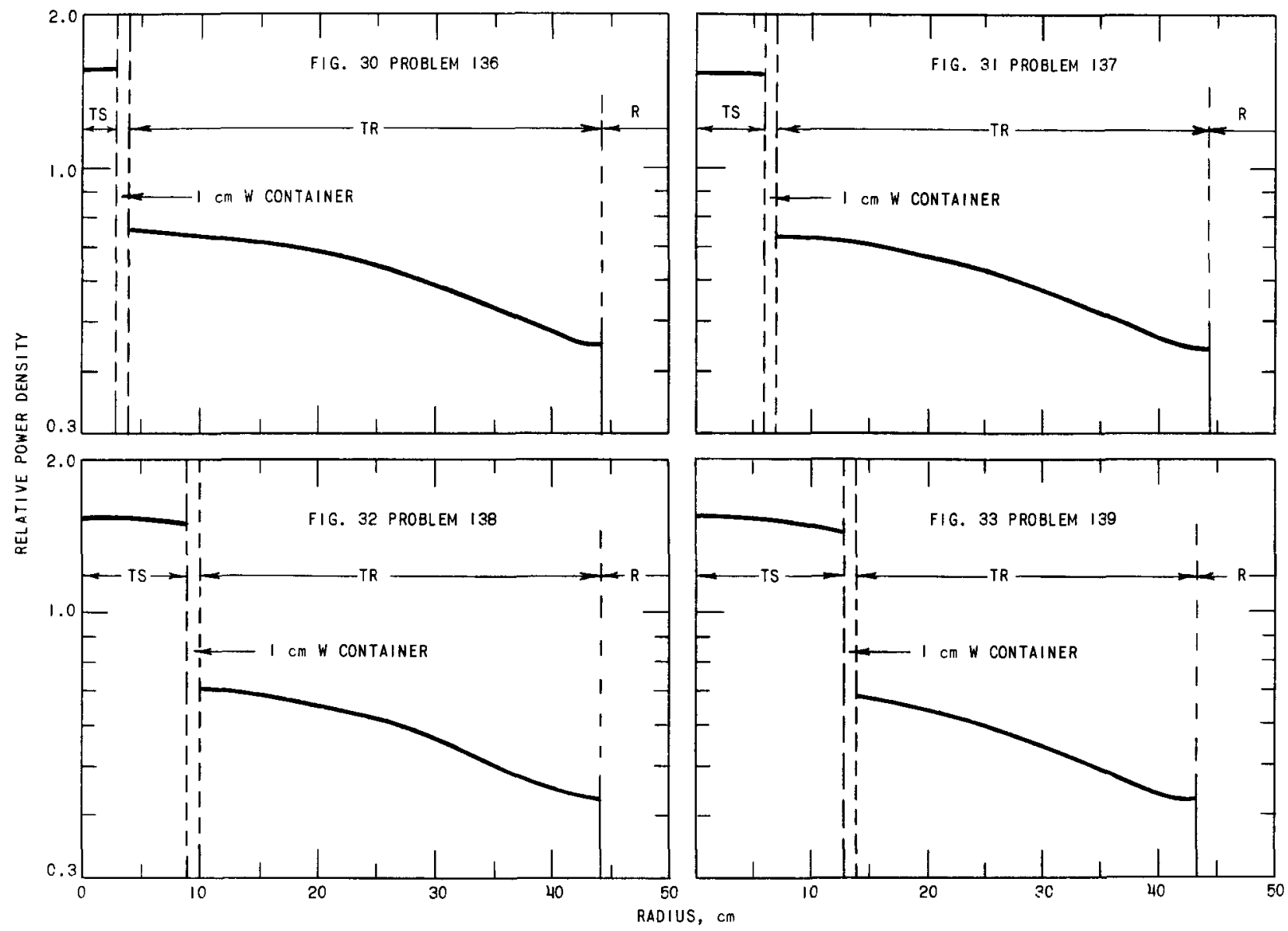

\section{$112-3989$}

Figs. 30-33. Relative Power Density Versus Radius for Fast Test Reactors with 3-,6-, 9-, and 13-cm-radius Test Sections (TS). (Dimensions and compositions for the problems shown are given in Table VII.)

density were normalized to a maximum of $10 \mathrm{MW} / \ell$, either at the center line or at the edge of the test section. The maximum-to-average power densities in the radial and axial directions were obtained from the power distribution plots of the test section and the test reactor. The ratio of the power density in the test section to that in the test reactor was also calculated from plots of power distribution. Summaries of the physics calculations for the $16-, 22-$, and $30-v / 0 \mathrm{UO}_{2}$-loaded test sections are presented in Tables VI, VII, and VIII, respectively. The plots of the maximum power density ratio versus the power output of the test reactor for the different uranium loadings of the test section are presented in Figs. 34, 35, and 36. Each line in these figures is plotted for a particular radial dimension of the test section and for both reactor types. 
Table XI

RESULTS OF PHYSICS CALCULATIONS FOR A FINITE CYLINDRICAL IEST REACTOR (TR) WITH A 16-V/O U02 TEST SECTION (TS)

\begin{tabular}{|c|c|c|c|c|c|c|c|c|c|c|c|c|c|}
\hline \multirow{3}{*}{$\begin{array}{l}\text { Problem } \\
\text { No }\end{array}$} & \multirow{3}{*}{$\begin{array}{c}\text { TR } \\
\text { Type }\end{array}$} & \multicolumn{4}{|c|}{ Composition } & \multirow{3}{*}{$\begin{array}{l}\text { TR Total } \\
\text { Loading } \\
\mathrm{kg} \mathrm{U}\end{array}$} & \multirow{3}{*}{$\begin{array}{c}\text { TS } \\
\text { Radius } \\
\mathrm{cm}\end{array}$} & \multirow{3}{*}{$\begin{array}{c}\text { Critical } \\
\text { Radius } \\
\mathrm{cm}\end{array}$} & \multirow{3}{*}{$\begin{array}{c}\text { TR } \\
\text { Power } \\
\text { MW }\end{array}$} & \multirow{2}{*}{\multicolumn{2}{|c|}{$\begin{array}{c}\text { Max/Avg Radial } \\
\text { Power Ratios }\end{array}$}} & \multirow{2}{*}{\multicolumn{2}{|c|}{$\begin{array}{c}\text { Power Density } \\
\text { Ratios }\end{array}$}} \\
\hline & & Loadıng & Coolant & Moderator Ratıo & $\mathrm{Fe}$ & & & & & & & & \\
\hline & & v/o $\mathrm{UO}_{2}^{*}$ & vo & $\mathrm{J}^{235 / \mathrm{Zr} \text { or } \mathrm{Be}}$ & w/o & & & & & TS & TR & $\operatorname{Max}$ & Avg \\
\hline 146 & $\mathrm{BeO}$ & 5 & 50 & 15 & 22 & 190 & 3 & 400 & 1218 & 106 & 127 & 213 & 257 \\
\hline 147 & $\mathrm{BeO}$ & 5 & 50 & 15 & 22 & 200 & 6 & 419 & 1441 & 110 & 123 & 202 & 227 \\
\hline 148 & $\mathrm{BeO}$ & 5 & 50 & 15 & 22 & 220 & 9 & 440 & 1631 & 112 & 120 & 198 & 211 \\
\hline 149 & $\mathrm{BeO}$ & 5 & 50 & 15 & 22 & 230 & 13 & 469 & 1830 & 117 & 118 & 195 & $1 \%$ \\
\hline 150 & $\mathrm{BeO}$ & 25 & 50 & 34 & 22 & 190 & 3 & 559 & 1632 & 107 & 135 & 296 & 373 \\
\hline 151 & $\mathrm{BeO}$ & 25 & 50 & 34 & 22 & 200 & 6 & 583 & 1988 & 113 & 134 & 264 & 315 \\
\hline 152 & $\mathrm{BeO}$ & 25 & 50 & 34 & 22 & 220 & 9 & 607 & 2236 & 120 & 133 & 256 & 284 \\
\hline 153 & $\mathrm{BeO}$ & 25 & 50 & 34 & 22 & 240 & 13 & 639 & 2512 & 126 & 129 & 250 & 257 \\
\hline 154 & $\mathrm{Zr}$ & $5-U$ & 50 & 84 & 0 & 510 & 3 & 445 & 2119 & 100 & 128 & 151 & 193 \\
\hline 155 & $\mathrm{Zr}$ & $5-U$ & 50 & 84 & 0 & 520 & 6 & 455 & 2228 & 100 & 125 & 152 & 191 \\
\hline 156 & $\mathrm{Zr}$ & $5-U$ & 50 & 84 & 0 & 550 & 9 & 469 & 2352 & 100 & 125 & 151 & 188 \\
\hline 157 & $\mathrm{Zr}$ & $5-U$ & 50 & 84 & 0 & 570 & 13 & 491 & 2523 & 100 & 122 & 152 & 185 \\
\hline 158 & $\mathrm{Zr}$ & $3-U$ & 50 & 15 & 0 & 960 & 3 & 787 & 3695 & 101 & 143 & 245 & 348 \\
\hline 159 & $Z r$ & $3-U$ & 50 & 15 & 0 & 990 & 6 & 800 & 3955 & 102 & 142 & 237 & 331 \\
\hline 160 & $\mathrm{Zr}$ & $3-U$ & 50 & 15 & 0 & 1020 & 9 & 815 & 4213 & 104 & 136 & 238 & 314 \\
\hline 161 & $\mathrm{Zr}$ & $3-U$ & 50 & 15 & 0 & 1040 & 13 & 836 & 4437 & 103 & 136 & 236 & 312 \\
\hline 162 & $\mathrm{BeO}$ & 125 & 50 & 70 & 22 & 200 & 3 & 820 & 2463 & 113 & & 394 & \\
\hline 163 & $\mathrm{BeO}$ & 125 & 50 & 70 & 22 & 220 & 6 & 852 & 3120 & 132 & & 325 & \\
\hline 164 & $\mathrm{BeO}$ & 125 & 50 & 70 & 22 & 220 & 9 & 882 & 3647 & 129 & & 304 & \\
\hline 165 & $\mathrm{BeO}$ & 125 & 50 & 70 & 22 & 250 & 13 & 919 & 4194 & 135 & & 293 & \\
\hline
\end{tabular}

Table VIII

RESULTS OF PHYSICS CALCULATIONS FOR A FINITE CYLINDRICAL TEST REACTOR (TR) WITH A 22-V/O U02 TEST SECTION (TS)

\begin{tabular}{|c|c|c|c|c|c|c|c|c|c|c|c|c|c|}
\hline \multirow{3}{*}{$\begin{array}{l}\text { Problem } \\
\text { No }\end{array}$} & \multirow{3}{*}{$\begin{array}{c}\text { TR } \\
\text { Type }\end{array}$} & \multicolumn{4}{|c|}{ Composition } & \multirow{3}{*}{$\begin{array}{l}\text { TR Total } \\
\text { Loadıng } \\
\text { kg U }\end{array}$} & \multirow{3}{*}{$\begin{array}{c}\text { TS } \\
\text { Radius } \\
\mathrm{cm}\end{array}$} & \multirow{3}{*}{$\begin{array}{c}\text { Critical } \\
\text { Radius } \\
\mathrm{cm}\end{array}$} & \multirow{3}{*}{$\begin{array}{c}\text { IR } \\
\text { Power } \\
\text { MW }\end{array}$} & \multirow{2}{*}{\multicolumn{2}{|c|}{$\begin{array}{c}\text { MaxiAvg Radıal } \\
\text { Power Ratios }\end{array}$}} & \multirow{2}{*}{\multicolumn{2}{|c|}{$\begin{array}{c}\text { Power Density } \\
\text { Ratios }\end{array}$}} \\
\hline & & Loadıng & Coolant & Moderator Ratıo & $\mathrm{Fe}$ & & & & & & & & \\
\hline & & v/o $\mathrm{UO}_{2}$ & v/o & $\mathrm{U}^{235 / \mathrm{Zr} \text { or } \mathrm{Be}}$ & v/o & & & & & TS & TR & $\operatorname{Max}$ & Avg \\
\hline 170 & $\mathrm{BeO}$ & 5 & 50 & 15 & 22 & 190 & 3 & 396 & 878 & 103 & 126 & $2 \%$ & 361 \\
\hline 171 & $\mathrm{BeO}$ & 5 & 50 & 15 & 22 & 190 & 6 & 405 & 956 & 107 & 123 & 286 & 328 \\
\hline 172 & $\mathrm{BeO}$ & 5 & 50 & 15 & 22 & 190 & 9 & 411 & 982 & 109 & 120 & 283 & 310 \\
\hline 173 & $\mathrm{BeO}$ & 5 & 50 & 15 & 22 & 190 & 13 & 413 & 915 & 109 & 116 & 298 & 317 \\
\hline 140 & $\mathrm{BeO}$ & 25 & 50 & 34 & 22 & 180 & 3 & 552 & 1122 & 107 & 137 & 412 & 529 \\
\hline 141 & $\mathrm{BeO}$ & 25 & 50 & 34 & 22 & 190 & 6 & 563 & 1278 & 113 & 133 & 383 & 453 \\
\hline 142 & $\mathrm{BeO}$ & 25 & 50 & 34 & 22 & 190 & 9 & 568 & 1322 & 114 & 132 & 379 & 436 \\
\hline 143 & $\mathrm{BeO}$ & 25 & 50 & 34 & 22 & 180 & 13 & 563 & 1213 & 117 & 127 & 402 & 439 \\
\hline 136 & $\mathrm{Zr}$ & $5-U$ & 50 & 84 & 0 & 500 & 3 & 441 & 1504 & 100 & 130 & 208 & 269 \\
\hline 137 & $\mathrm{Zr}$ & $5 U$ & 50 & 84 & 0 & 500 & 6 & 443 & 1495 & 100 & 129 & 208 & 269 \\
\hline 138 & $\mathrm{Zr}$ & $5 \mathrm{U}$ & 50 & 84 & 0 & 480 & 9 & 440 & 1387 & 101 & 127 & 219 & 275 \\
\hline 139 & $\mathrm{Zr}$ & $5-U$ & 50 & 84 & 0 & 430 & 13 & 431 & 1194 & 104 & 128 & 226 & 281 \\
\hline 270 & $\mathrm{Zr}$ & $3-U$ & 25 & 22 & 0 & 880 & 3 & 754 & 2238 & 100 & 150 & 333 & 500 \\
\hline 272 & $\mathrm{Zr}$ & $3-11$ & 25 & 22 & 0 & 870 & 6 & 752 & 2315 & 103 & 149 & 342 & 494 \\
\hline 274 & $\mathrm{Zr}$ & $3-1$ & 25 & 22 & 0 & 820 & 9 & 738 & 2197 & 101 & 149 & 343 & 504 \\
\hline 276 & $\mathrm{Zr}$ & $3-U$ & 25 & 22 & 0 & 720 & 13 & 694 & 1814 & 100 & 152 & 354 & 535 \\
\hline 271 & $\mathrm{Be}$ & 5 & 40 & 34 & 25 & 130 & 3 & 321 & 661 & 106 & 121 & 264 & 304 \\
\hline 273 & $\mathrm{Be}$ & 5 & 40 & 34 & 25 & 130 & 6 & 333 & 757 & 110 & 119 & 247 & 267 \\
\hline 275 & $\mathrm{Be}$ & 5 & 40 & 34 & 25 & 130 & 9 & 343 & 783 & 112 & 117 & 248 & 259 \\
\hline 277 & $\mathrm{Be}$ & 5 & 40 & 34 & 25 & 130 & 13 & 353 & 723 & 118 & 112 & 259 & 241 \\
\hline 166 & $\mathrm{BeO}$ & 125 & 50 & 70 & 22 & 200 & 3 & 812 & 1743 & 110 & 152 & 521 & 718 \\
\hline 167 & $\mathrm{BeO}$ & 125 & 50 & 70 & 22 & 210 & 6 & 827 & 2051 & 118 & 147 & 471 & 584 \\
\hline 168 & $\mathrm{BeO}$ & 125 & 50 & 70 & 22 & 210 & 9 & 833 & 2115 & 122 & 146 & 465 & 556 \\
\hline 169 & $\mathrm{BeO}$ & 125 & 50 & 70 & 22 & 200 & 13 & 821 & 1941 & 125 & 144 & 488 & 563 \\
\hline
\end{tabular}

Table VIII

RESULTS OF PHYSICS CALCULATIONS FOR A FINITE CYLINDRICAL TEST REACTOR (TR) WITH A 30-v/o U02 IEST SECTION (TS)

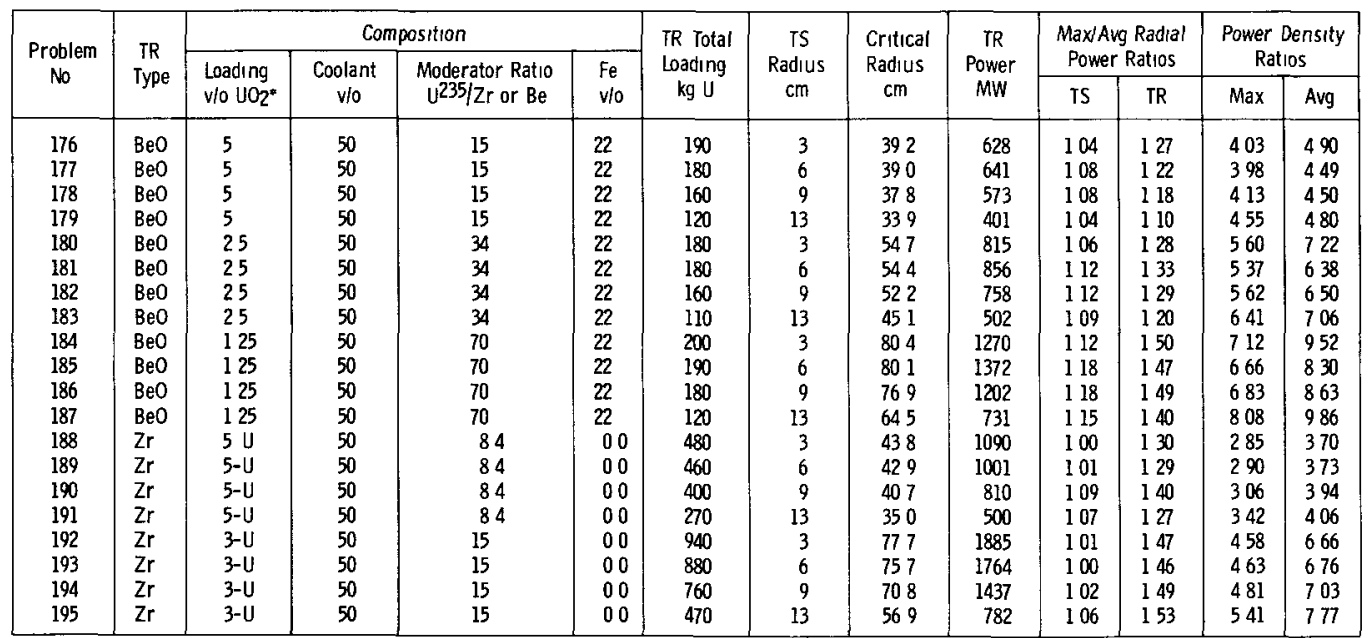




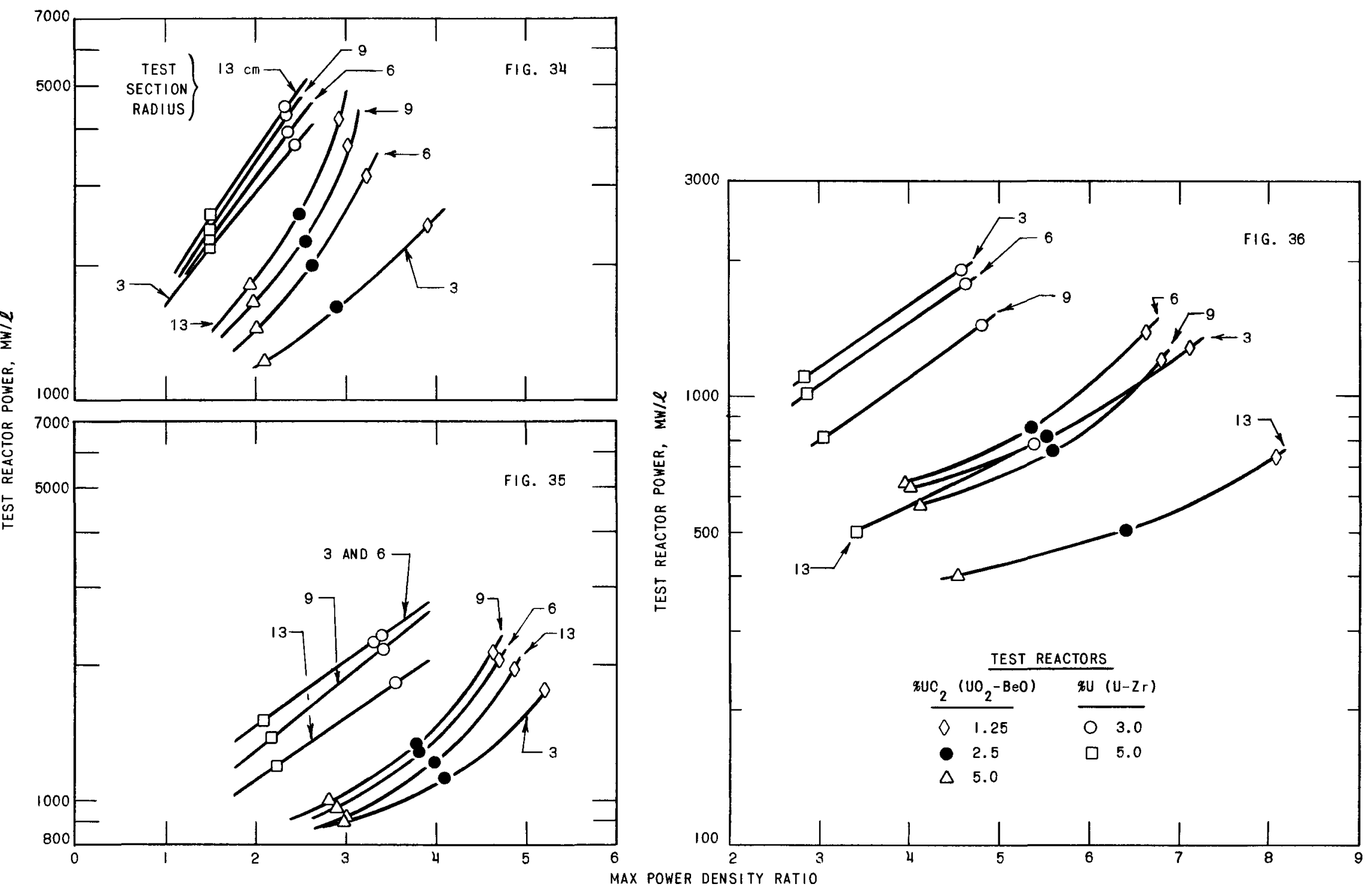

$112-3662$ Rev.

Figs. 34-36. Test Reactor Power Versus Maximum Power Density Ratio for 16-, 22-, and 30-v/o Uranium Oxide Test Sections 
The three parameters under study: loading of the reactor, loading of the test section, and the radial dimension of the test section, influenced the total power and power density ratios in the test reactor. The most heavily loaded test section, containing $30 \mathrm{v} / \mathrm{o} \mathrm{UO}_{2}$, resulted in the lowest total power for a particular power density ratio. For the $\mathrm{UO}_{2}-\mathrm{BeO}$ test reactor, the total power, at a power density ratio of 3 and a test section radius of $3 \mathrm{~cm}$, was $1650 \mathrm{MW}$ for a $16-\mathrm{v} / \mathrm{o} \mathrm{UO}_{2}$ loading; $900 \mathrm{MW}$ for a $22 \mathrm{-v} / \mathrm{o}$ $\mathrm{UO}_{2}$ loading; and approximately $575 \mathrm{MW}$ for a $30-\mathrm{v} / \mathrm{o} \mathrm{UO}_{2}$ loading in the test section (see Figs. 34, 35, and 36). In all cases, the ratio of the power density increased as the total power production increased. Therefore, some compromise is necessary between these two quantities. Also, of all test reactors studied, the $\mathrm{UO}_{2}-\mathrm{BeO}$ test reactors produced less power than the $\mathrm{U}-\mathrm{Zr}$ test reactors for any particular maximum power density ratio. It is possible, however, that if large power density ratios were required, such as 10 or 20 to 1 , a fast dilute system might produce a smaller quantity of power; but at such a ratio the total power production would eliminate both types of test reactors from consideration.

Another result of these calculations was the influence of the size of the test section on the power production. To make the test facility as flexible as possible, it would be ideal to have the test reactor produce approximately the same amount of power whether or not a single element or a large group of elements were being tested. This feature was present in some of the test reactors. For the $22 \mathrm{-v} / \mathrm{O} \mathrm{UO}_{2}$ test section and a $\mathrm{UO}_{2}-\mathrm{BeO}$ test reactor, the test reactor power ranged between 900 and $1050 \mathrm{MW}$ (see Fig. 35). This was applicable for the complete range of test section sizes at a power density ratio of 3 to 1 . In many cases, the critical radius of the reactor changed little for the various test-section radii. This feature also improved the flexibility of the test reactors. The relationship between test section size and total power, in the case of the fast dilute reactor, was the same for all test-section loadings. For a particular power density ratio, the total power in a U-Zr reactor decreased as the size of the test section was increased. This was not always the case for the $\mathrm{UO}_{2}-$ $\mathrm{BeO}$ reactor. Even in these exceptions the size of the test section did not have as large an influence on the relationship between total power and maximum power density ratio.

In the range of parameters that were studied in this section, the $\mathrm{UO}_{2}-\mathrm{BeO}$ fueled test reactor appeared to be more attractive than the fast dilute system. For example, in the case of the $30 \mathrm{-v} / \mathrm{O} \mathrm{UO}_{2}$-loaded test section, the $\mathrm{UO}_{2}-\mathrm{BeO}$ reactor produced about half the power that a fast dilute system would at the same maximum power density ratio. 
2. Criticality Calculations for a Test Section with a Nonmoderating Reflector

The critical radius for a reflected test section was determined for the 22 - and $30-\mathrm{v} / \mathrm{o} \mathrm{UO}_{2}$-loaded test sections. Nickel, iron, and zirconium were considered as possible reflectors. Reflectors composed of moderating materials were excluded because of the resulting power peaks near the reflector. The results indicated that the critical radius of a reflected system was about one-half that of a bare system and the volume was, therefore, about one-fourth. The radial power distribution exhibited no peaks at the reflector-core interface and had the shape of a "chopped $J_{0}$ " function.

The advantage of a reflected test section is the elimination of the test reactor. The reflector would be much less expensive than a reactor and produce very little heat compared with the hundreds of megawatts generated by a reactor. The disadvantages of the reflector are that the test section must be large and that there would be little versatility in the facility. Single-element testing would not be possible in a reflected test section. However, as the aims of a testing program become clearer, the relative merits of a reflected test section and a test reactor can be better evaluated. 


\section{HEAT REMOVAL FROM TEST REACTOR CORES}

The test reactors described in the previous section were sodiumcooled. It was assumed that the reactor heat would be finally dumped by passing the sodium through an auxiliary heat-exchange system. Throughout the calculations reported in this section, it was assumed that the reactor cores would be composed of rod-type fuel elements in a uniformly spaced lattice. Coolant flow was assumed to be orificed to correspond with the radial power distribution in the core. Although, in this analysis, an attempt has been made to stay within the confines of conventional heatremoval technology, it was recognized that the reactor cores, comprised of the two fuels under consideration, namely, the $\mathrm{UO}_{2}-\mathrm{BeO}$ (ceramic) and the U-Zr alloy (metallic), had not been operated in the range of 1 to $3 \mathrm{MW} / \ell$ with sodium coolant. However, a great deal of operating experience is available with water-cooled reactors and even in some liquid metal-cooled reactors fueled with $\mathrm{U}-\mathrm{Zr}$ alloys, and the fabrication techniques for this fuel are well known. In the case of the $\mathrm{UO}_{2}-\mathrm{BeO}$ fuel, fabrication techniques have been developed, $(2,3)$ but actual operating experience is quite limited. Also, with the high heat fluxes required to attain the high power densities of interest here, thermal stresses in the fuel cladding could become limiting.

A. BeO-UO $\mathrm{UO}_{2}$-fueled Test Reactor

\section{Heat Transfer Analysis}

The heat transfer analysis of the $\mathrm{UO}_{2}-\mathrm{BeO}$-fueled systems was performed as follows:

With a selected rod diameter, the average fuel power density is given by the following equation:

$$
Q=\frac{16 \int k(\theta) d \theta}{D^{2} R_{a} R_{r}}
$$

In addition, fixing the temperature rise in the core, coolant velocity, and length determines the required core coolant fraction according to the following equations:

$$
\begin{aligned}
& \mathrm{D} / \mathrm{D}_{\mathrm{H}}=\mathrm{GC}_{\mathrm{p}} \Delta \mathrm{T} / \mathrm{Ql} ; \\
& \mathrm{v}_{\mathrm{C}}=\frac{1}{\left(\mathrm{D} / \mathrm{D}_{\mathrm{H}}\right)+1} .
\end{aligned}
$$

The average power density in the core is then given by

$$
Q^{\prime}=Q\left(1-v_{C}\right) .
$$


Having thus obtained the average power density in the core, the coolant film temperature drop is calculated in the following manner.

For the case of uniform axial power production and constant $\mathrm{C}_{\mathrm{p}}$, the coolant temperature rise to a point $\chi$ along the core length is given by

$$
\Delta t=\left(t_{2}-t_{1}\right) \chi / l
$$

Coolant film temperature drop is given by

$$
\dot{\Delta t}=P R_{a} R_{r} C_{1} / \pi \ell N D h
$$

The cladding surface temperature is given by the sum of Eqs. (5) and (6):

$$
t_{S}=t_{1}+\left(t_{2}-t_{1}\right) \frac{\chi}{l}+\frac{P R_{a} R_{r} C_{1}}{\pi l N D h}
$$

The factor $C_{1}$ is a correction for the fact that the maximum heat flux generally occurs at the core geometric center axially, whereas the maximum cladding surface temperatures shift toward the exit end of the core. Accordingly, $C_{1}$ depends upon the maximum to average axial power distribution in the core at a particular position along a coolant channel. For all the cases studied the axial maximum to average power ratio $R_{a}$ was taken as 1.3 and a chopped cosine distribution was assumed; hence

$$
C_{1}=0.3624 \cos 2.40\left(\frac{\chi}{\ell}\right)+0.9320 \sin 2.40\left(\frac{\chi}{\ell}\right)
$$

Substitution of Eq. (8) into Eq. (7) and the substitution

$$
(\triangle \mathrm{t}) \mathrm{m}=\mathrm{PR}_{\mathrm{a}} \mathrm{R}_{\mathrm{r}} / \pi \ell \mathrm{NDh}
$$

gives

$$
\mathrm{t}_{\mathrm{s}}=\mathrm{t}_{1}+\left(\mathrm{t}_{2}+\mathrm{t}_{1}\right) \frac{\chi}{\ell}+(\Delta \mathrm{t})_{\mathrm{m}}\left[0.3624 \cos 2.40\left(\frac{\chi}{\ell}\right)+0.9320 \sin 2.40\left(\frac{\chi}{l}\right)\right]
$$

To find the point of maximum temperature, Eq. (9) is differentiated with respect to $\chi$ and set equal to zero:

$$
t_{2}-t_{1}=(\Delta t)_{m}\left[0.8698 \sin 2.40(X / \ell)_{h}-2.237 \cos 2.40(X / \ell)_{h}\right] .
$$

Elimination of the parameter $(\Delta t)_{m}$ by dividing Eq. (10) by Eq. (9) gives

$\frac{t_{2}-t_{1}}{t_{s}-t_{1}-\left(t_{2}-t_{1}\right)(\chi / \ell)_{h}}=\frac{0.8696 \sin 2.40(\chi / \ell)_{h}-2.237 \cos 2.40(\chi / \ell)_{h}}{0.9320 \sin 2.40(\chi / \ell)_{h}+0.3624 \cos 2.40(\chi / \ell)_{h}}$. 
Under the assumptions used in deriving Eq. (5), Eq. (11) expresses the location of the maximum surface temperature in terms of the permissible surface temperature, coolant inlet temperature, and coolant temperature rise. Equation (11) is solved by trial and error for $(\chi / \ell)_{h}$, and this result is used in Eq. (10) to obtain the correct value for $(\Delta t) \mathrm{m}$. This establishes the relationship between the maximum film drop $(\Delta t)_{m}$, the coolant outlet temperature $t_{2}$, and the fuel surface temperature $t_{s}$.

Furthermore, it can be shown that

$$
(\Delta t)_{\mathrm{m}}=\left[4 \int \mathrm{k}(\theta) \mathrm{d} \theta\right] / \mathrm{Dh}
$$

Therefore, it is apparent that $(\Delta t)_{m}$ and, hence, the coolant outlet temperature are fixed for a given fuel and rod diameter, and fuel surface temperature; and it is only necessary to evaluate the heat transfer coefficient to solve Eq. (12) for $(\Delta t)_{m}$. Heat transfer coefficients are calculated by the use of the Lubarsky-Kaufmann equation:

$$
\mathrm{Nu}=0.625(\mathrm{Pe})^{0.4}
$$

where

$$
\begin{aligned}
& \mathrm{Nu}=\text { Nusselt Number }=\mathrm{h} \mathrm{D}_{\mathrm{H}} / \mathbf{k} ; \\
& \mathrm{Pe}=\text { Peclet Number }=\mathrm{D}_{\mathrm{H}} \mathrm{GC}_{\mathrm{P}} / \mathrm{k} .
\end{aligned}
$$

The value of $D_{H}$ is obtained from Eq. (2), and it is possible to solve directly for $h$ and $t$, and hence $(\Delta t)_{m}$. By using the generalized solutions of Eqs. (10) and (11) presented in Fig. 37, it is then possible to obtain the corresponding coolant outlet temperature for a given maximum cladding surface temperature.

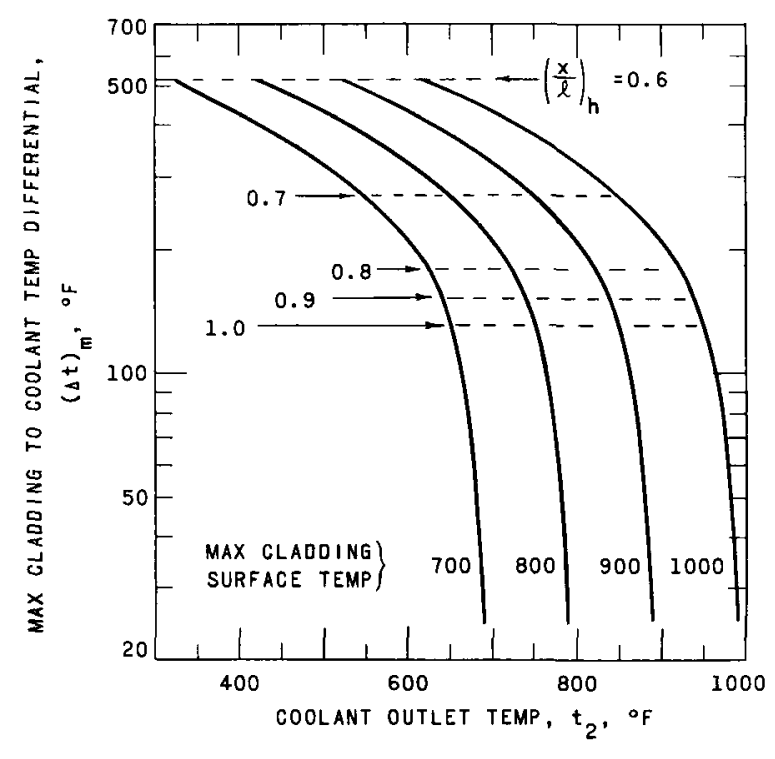

Fig. 37

Maximum Cladding to Coolant Temperature Differential Versus Coolant Outlet Temperature 


\section{Limitations Imposed by Fuel Cladding}

The mechanical and thermal properties of the fuel cladding may eventually limit the power output. Fuel-element claddings are subject to two principal stresses: (a) stresses arising from mechanical pressure as a result of accumulation of fission product gases with time, and (b) thermal stresses due to the substantial temperature drop across the cladding wall. In the calculations which follow the component of stress due to fission gas pressure was omitted, so that the analysis was concerned only with the thermal stress component. An equation relating the cladding thermal stress to the power density in a fuel rod was developed as follows.

For a thin-walled cylinder, the axial and tangential thermal stresses are equal and are given by

$$
\sigma_{t}=E \alpha(\Delta t)_{c} / 2(1-\nu)
$$

Equation (14) is conservative by $5 \%$ for a value of $\mathrm{D} / \epsilon=10$. For larger ratios of diameter to wall thickness, the error is less. It is possible to relate the power density in the fuel rod to the thermal stress, since the heat flux, thermal conductivity of the cladding material, and cladding thickness determine the temperature drop across the cladding. For a unit length of rod, the heat generated is

$$
\mathrm{m}=\mathrm{Q} \pi \mathrm{D}^{2} / 4
$$

Hence, the heat flux is

$$
\mathrm{q}=\mathrm{m} / \mathrm{A}=\mathrm{QD} / 4
$$

Further,

$$
(\Delta t)_{c}=q \in / k \text {. }
$$

Substitution of Eq. (16) into Eq. (17) gives

$$
(\Delta t)_{C}=Q D \in / 4 k
$$

Substitution of Eq. (18) into Eq. (14) and rearrangement give

$$
Q=8(1-\nu) k \sigma_{t} / E \alpha \in D
$$

or, in terms of the average power density of the core,

$$
Q=8(1-\nu) k \sigma_{t} / E \alpha \in D R_{a} R_{r} .
$$

Equation (20) then gives the permissible power density in a fuel rod as limited by the cladding. 


\section{Results of Power Density Calculations}

The heat-transfer analysis of the $\mathrm{UO}_{2}-\mathrm{BeO}$-fueled systems was based on the following conditions:

(a) Properties of sodium as coolant:

$$
\begin{aligned}
\mathrm{C}_{\mathrm{p}} & =0.31 \mathrm{Btu} /(\mathrm{lb})\left({ }^{\circ} \mathrm{F}\right) ; \\
\mathrm{k} & =44 \mathrm{Btu} /(\mathrm{hr})(\mathrm{ft})\left({ }^{\circ} \mathrm{F}\right) ; \\
\rho & =54 \mathrm{lb} / \mathrm{ft}^{3} ;
\end{aligned}
$$

(b) Average coolant velocity $=30 \mathrm{ft} / \mathrm{sec}$;

(c) Coolant temperature rise across core $=300^{\circ} \mathrm{F}$;

(d) Core height $=2.85 \mathrm{ft}(87 \mathrm{~cm})$;

(e) Axial maximum to average power ratio = 1.3;

(f) Radial maximum to average power ratio $=1.4$;

(g) Maximum cladding temperature $=700^{\circ} \mathrm{F}$;

(h) Two cases for fuel thermal rating: $\int \mathrm{k}(\theta) \mathrm{d} \theta=100$ and $150 \mathrm{~W} / \mathrm{cm}$

Calculations were done for rod diameters of $0.250,0.375$, and $0.50 \mathrm{in}$. The calculated power density as a function of rod diameter for the
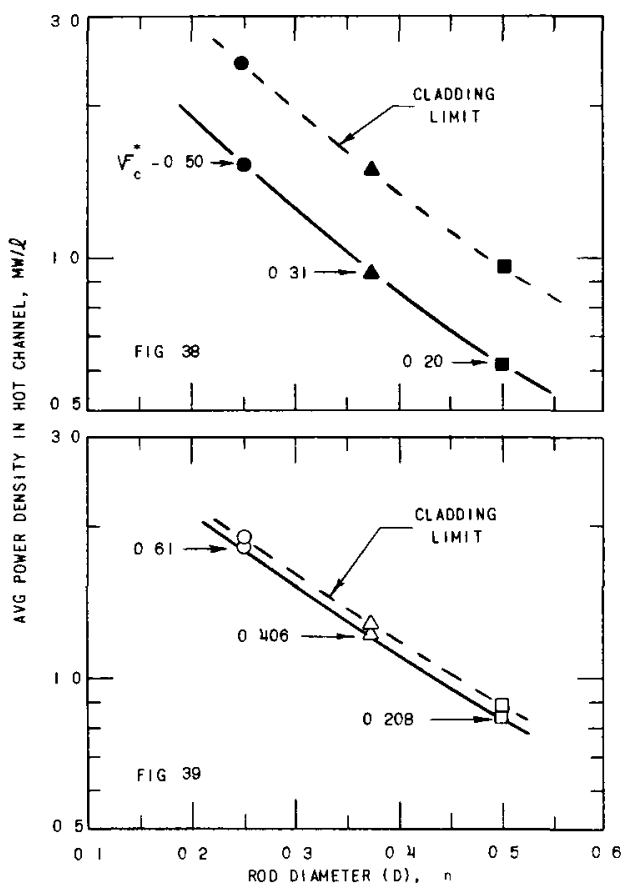

* COOLANT Volume fraction

$112-3986$

Figs. 38 -39. Average Power Density in Hot Chan nel Versus Rod Diameter for a Beryllium Oxıde-Uranium Oxıde Fuel Element wath $\int k(\theta) d \theta$ of $100 \mathrm{~W} / \mathrm{cm}$ and $150 \mathrm{~W} / \mathrm{cm}$. two fuel elements with thermal ratings of 100 and $150 \mathrm{~W} / \mathrm{cm}$ are given in Figs. 38 and 39 , respectively In these figures, the power density plotted along the ordinate is the average power density in the hot channel; the refore, the maximum power density in the core is obtained by multiplying the average value, given in the figures, by 13 . In each figure the dotted line represents the cladding limit, calculated by use of Eq. (20), which is conservatively based on the properties of 347 stainless steel at $1000^{\circ} \mathrm{F}$. These properties are listed in Table IX. Temperature profiles calculated for a hot channel fuel element for the two fuel thermal ratings and a rod diameter of 0.25 in are given in Figs 40 and 41 . The coolant outlet temperatures are obtained by using Eq (13) to calculate the heat transfer coefficient, solving for $(\Delta t)_{\mathrm{m}}$, and then reading off the value from Fig 37 for a surface temperature of $700^{\circ} \mathrm{F}$. A value of $5000 \mathrm{Btu} /(\mathrm{hr})\left(\mathrm{ft}^{2}\right)\left({ }^{\circ} \mathrm{F}\right)$ was assumed for the contact resistance between the inside of the cladding and the 
fuel surface to obtain the temperature profiles given in the figures. The thermal conductivity of the $\mathrm{UO}_{2}-\mathrm{BeO}$ fuel is $20 \mathrm{Btu}-(\mathrm{hr})(\mathrm{ft})\left({ }^{\circ} \mathrm{F}\right)$ over the temperature range involved in the calculations. A summary of the six cases calculated for the $\mathrm{BeO}$ fuel is presented in Table $\mathrm{X}$; in all cases the maximum cladding surface temperature was taken as $700^{\circ} \mathrm{F}$.

Table IX

PROPERTIES OF TYPE-347 STAINLESS STEEL AT $1000^{\circ} \mathrm{F}$

Young's modulus (E)

Coefficient of expansion $(\alpha)$

Thermal conductivity $(k)$

Yield strength

Poisson's ratio ( $\nu$ )
$21.4 \times 10^{6} \mathrm{psi}$

$16.5 \times 10^{-6} /{ }^{\circ} \mathrm{C}$

$0.237 \mathrm{~W} /(\mathrm{cm})\left({ }^{\circ} \mathrm{C}\right)$

27,000 psi

0.3

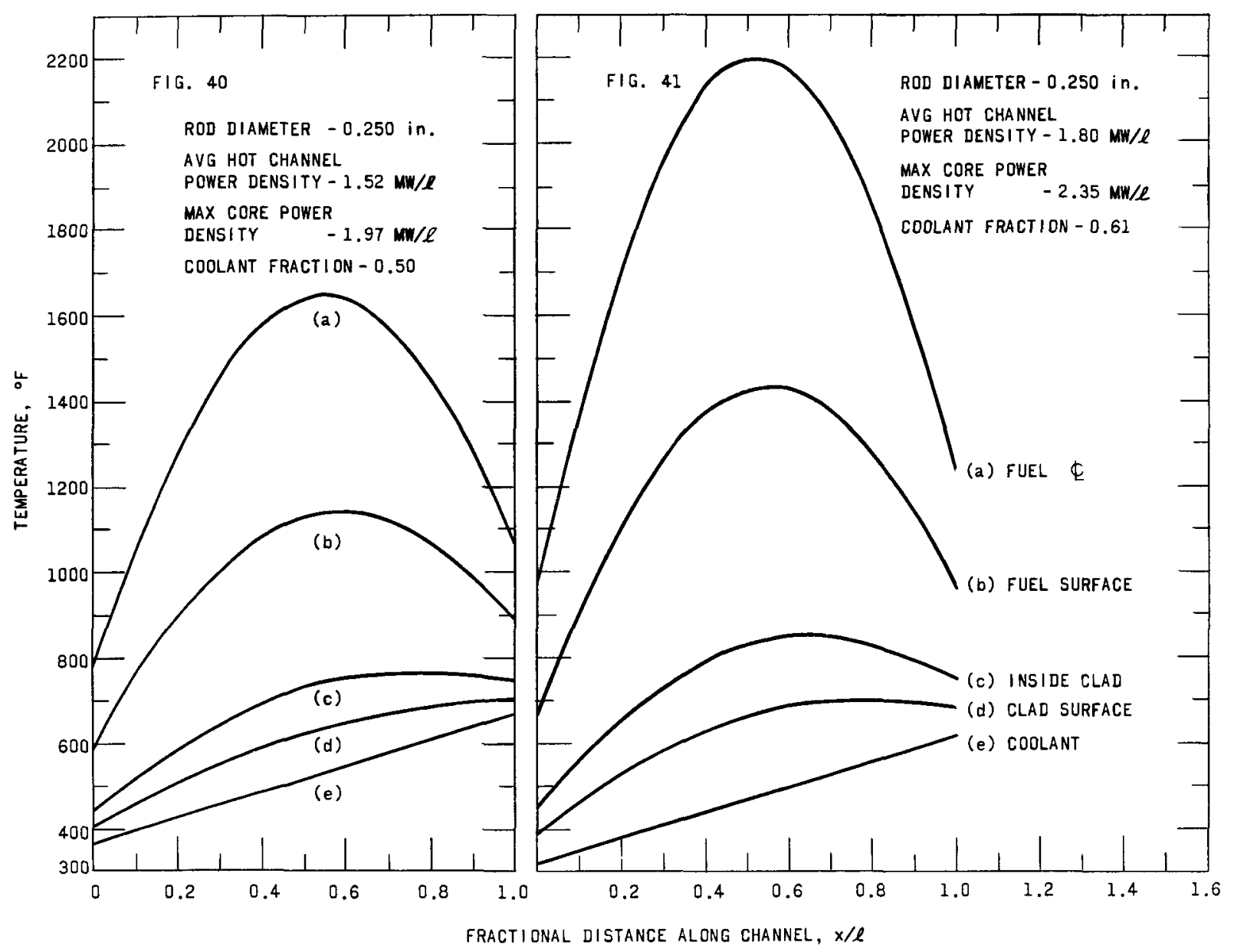

$112-3996$

Figs. 40-41. Temperature Profile in Hot Channel for a Beryllium OxideUranium Oxide Fuel Element with a $\int k(\theta) d \theta$ of $100 \mathrm{~W} / \mathrm{cm}$ and $150 \mathrm{~W} / \mathrm{cm}$. 
Table $\mathrm{X}$

SUMMARY OF HEAT TRANSFER CALCULATIONS FOR UO, -BeO-FUELED TEST REACTOR

\begin{tabular}{|c|c|c|c|c|c|c|c|}
\hline $\begin{array}{l}\text { Fuel Rod } \\
\text { Diameter } \\
\text { in }\end{array}$ & $\begin{array}{c}\text { Cladding } \\
\text { Thickness, } \\
\text { in }\end{array}$ & $\begin{array}{c}\int \mathrm{k}(\theta) \mathrm{d} \theta \\
\mathrm{W} / \mathrm{cm}\end{array}$ & $\begin{array}{l}\text { Coolant } \\
\text { Volume } \\
\text { Fraction }\end{array}$ & $\begin{array}{c}\text { Max Core } \\
\text { Power } \\
\text { Density, } \\
\text { MW } / \ell\end{array}$ & $\begin{array}{l}\text { Avg Core } \\
\text { Power } \\
\text { Density, } \\
\text { MW/l }\end{array}$ & $\begin{array}{c}\text { Max Heat } \\
\text { Flux } \\
10^{6} \mathrm{Btu} /(\mathrm{hr})\left(\mathrm{ft}^{2}\right)\left({ }^{\circ} \mathrm{F}\right)\end{array}$ & $\begin{array}{l}\text { Coolant } \\
\text { Outlet } \\
\text { Temp, }{ }^{\circ} \mathrm{F}\end{array}$ \\
\hline 0250 & 0010 & 100 & 050 & 197 & 108 & 199 & 665 \\
\hline 0375 & 0015 & 100 & 031 & 121 & 067 & 133 & 680 \\
\hline 0500 & 0020 & 100 & 020 & 080 & 044 & 100 & 688 \\
\hline 0250 & 0010 & 150 & 061 & 235 & 129 & 299 & 615 \\
\hline 0375 & 0015 & 150 & 041 & 157 & 086 & 199 & 665 \\
\hline 0500 & 0020 & 150 & 028 & 107 & 059 & 149 & 678 \\
\hline
\end{tabular}

As can be seen from these results, it is theoretically possible to obtain peak power densities greater than $2 \mathrm{MW} / \ell$ by using $\mathrm{BeO}$ fuel in the form of 0.25 -in.-diameter rods while keeping the center of the fuel well below the melting point and also maintaining acceptable thermal stresses in the fuel cladding.

\section{B. U-Zr Alloy Fueled Test Reactor}

The method used for the heat transfer analysis of the U-Zr-fueled reactor was similar to that of the $\mathrm{UO}_{2}-\mathrm{BeO}$ reactor. The calculations were based on the conditions (a) through ( $\mathrm{g}$ ) listed in part A. 3 of this section. Preliminary calculations indicated that the fuel temperature at the center line of the fuel element limits the power density under the specified conditions. The analys is then consisted of calculating the heat transfer at the location of the maximum fuel temperature, that is, at the vertical midplane of the hot channel.

The melting point of the $\mathrm{U}-\mathrm{Zr}$ alloy is about $3200^{\circ} \mathrm{F}$. A conservative value for the maximum fuel temperature was estimated to be $2500^{\circ} \mathrm{F}$. Allowable values for the other temperatures in the fuel element were $700^{\circ} \mathrm{F}$ at the outside of the clad and $1500^{\circ} \mathrm{F}$ at the inside of the clad. Since the $\mathrm{U}-\mathrm{Zr}$ fuel was clad with zirconium, it was assumed the thermal resistance between the fuel and the clad was negligible. The results for three power densities and three fuel rod diameters are presented in Table XI.

Table XI

HEAT TRANSFER ANALYSIS OF A U-Zr ALLOY-FUELED REACTOR FOR VALUES OF POWER DENSITY AND ROD DIAMETER

\begin{tabular}{|c|c|c|c|c|c|c|c|c|c|c|}
\hline Max Power Density & MW/l of core & 1 & 1 & 1 & 2 & 2 & 2 & 25 & 25 & 25 \\
\hline Rod Diameter & in. & $1 / 8$ & $1 / 4$ & $1 / 2$ & $1 / 8$ & $1 / 4$ & $1 / 2$ & $1 / 8$ & $1 / 4$ & $1 / 2$ \\
\hline Coolant Velocity & $\mathrm{ft} / \mathrm{sec}$ & 337 & 337 & 337 & 429 & 429 & 429 & 422 & 422 & 422 \\
\hline Sodium Fraction & - & 035 & 035 & 035 & 055 & 055 & 055 & 070 & 070 & 070 \\
\hline Thermal Conductivity of Fuel & $\mathrm{Btu} /(\mathrm{hr})(\mathrm{ft})\left({ }^{\circ} \mathrm{F}\right)$ & 8 & 8 & 8 & 8 & 8 & 8 & 8 & 8 & 8 \\
\hline Inlet Coolant Temp & of & 300 & 300 & 300 & 300 & 300 & 300 & 300 & 300 & 300 \\
\hline At Vertıcal Midplane & & & & & & & & & & \\
\hline Inside Clad Temp & ${ }^{\circ} \mathrm{F}$ & 479 & 559 & 861 & 507 & 660 & 1259 & 520 & 715 & 1463 \\
\hline Centerlıne Fuel Temp & ${ }^{\circ} \mathrm{F}$ & 604 & 1,063 & 2879 & 756 & 1,668 & 5295 & 831 & 1,975 & 6.508 \\
\hline Thermal Stress in Clad & psi & 462 & 1851 & 7463 & 925 & 3703 & 14926 & 1,157 & 4628 & 18658 \\
\hline
\end{tabular}


From the results, it is seen that the temperature and thermal stress of the clad are below their allowable values for a maximum fuel temperature.

As stated in the introduction of this report, the investigation for a test reactor was based on near-future technology and a maximum power density in the test reactor of 2 to $2.5 \mathrm{MW} / \ell$. The heat transfer calculations indicated that a $1 / 8$-in.- and a 1/4-in.-diameter fuel element could achieve a maximum power density of $2.5 \mathrm{MW} / \ell$, and therefore a $\mathrm{U}-\mathrm{Zr}$-fueled test reactor would meet the maximum power density requirement.

\section{CONCLUSIONS OF THE STUDY}

In the beginning of this study it was assumed that the test section operated at power densities up to $10 \mathrm{MW} / \ell$. The results of Section III showed that a sodium-cooled test reactor can operate at 2 to $2.5 \mathrm{MW} / \ell$. If the upper limit of the power density in the test section $(10 \mathrm{MW} / \ell)$ is considered, the maximum power density ratio would be 4 or 5 . With a value of 5 for the maximum power density ratio, only a $\mathrm{UO}_{2}-\mathrm{BeO}$ reactor with a loading of $30 \mathrm{-v} / \mathrm{o}$ $\mathrm{UO}_{2}$ in the test section appears to be practical. For this situation, test reactor power would be in the range of 420 to $780 \mathrm{MW}$, depending upon the size of the test section. In the case of the $22-\mathrm{v} / \mathrm{O} \mathrm{UO}_{2}$ loading in the test section, the total power would be in excess of $1500 \mathrm{MW}$ at the same power density ratio. For the fast dilute reactor, the power, at a maximum power density ratio of 5 , would be over $1500 \mathrm{MW}$ for all test section loadings. Therefore, it was concluded that test fuel elements loaded as heavily as possible with $\mathrm{U}^{235}$ and a $\mathrm{UO}_{2}-\mathrm{BeO}$-fueled test reactor would constitute a feasible test facility.

Even in the most favorable case, however, the total power production of the $\mathrm{UO}_{2}-\mathrm{BeO}$ test reactor was still quite large. In this connection, there are possibilities for optimization of the test reactor which as yet have not been fully explored. One possibility would be to use a variable loaded reactor for the $\mathrm{UO}_{2}-\mathrm{BeO}$ test reactor. In the power distribution plots (Figs. 26 through 29) the power is depressed near the test section, reaches a maximum about $10 \mathrm{~cm}$ from the test section, and then decreases with increasing radius. It might be possible to improve the maximum power density ratio by using the heavier uranium loading near the test section and a lighter loading further out. There is also the possibility that another type of reflector would reduce the critical size and, therefore, decrease the total power produced. Lead might be a better reflector than nickel, and a mixture of beryllium and lead or beryllium and nickel might soften the spectrum sufficiently to flatten the power distribution without producing large power peaks at the core-reflector interface.

As stated, it is desirable to have as heavy a loading as possible in the test section. The same favorable results, however, could be achieved by use of a more reactive material as the fuel for the test section. A possibility in this case would be to substitute $\mathrm{U}^{233}$ for $\mathrm{U}^{235}$ : however, only a 
limited amount of $\mathrm{U}^{233}$ is available. These possible improvements do not change the general conclusions of the study, that is, that a large amount of power (hundreds of megawatts) is required to obtain a maximum power density ratio of 4 or 5 .

Although the effort in this study was directed primarily toward the ANL $\mathrm{UO}_{2}$-tungsten fast rocket reactor concept, some preliminary calculations were run for the Kiwi uranium-graphite fuel. The results of these calculations indicate that the spectrum of a Kiwi reactor is similar to that for the $\mathrm{UO}_{2}-\mathrm{BeO}$ epithermal test reactor; hence, the insertion of the uraniumgraphite fuel into such a test reactor should not introduce a serious perturbation. Accordingly, the prospects for a "universal" test reactor having the capability for testing rocket fuel elements of fast as well as epithermal spectrum reactors appear to be good.

In the absence of knowledge as to the degree of simulation required for the fuel-element tests in the test reactor, the emphasis in this study has been placed on close simulation of the actual neutron spectra and power distributions in both large and small clusters of test elements. Consequently, the test reactor concept which has evolved is quite versatile and is suitable for testing a range of test sample sizes. There remains, however, the reconciliation of this flexibility with the large test reactor power output. 


\section{APPENDIX A}

\section{SCOPE OF TESTING PROGRAMS REQUIRED TO ASSURE A GIVEN RELIABILITY FOR A NUCLEAR ROCKET ENGINE}

The overall reliability of the rocket boosters in the United States space program has been 68\% through July 1, 1961.(4) Because of the large expense associated with even relatively modest space probes, every effort is being made to increase this reliability; and success is being achieved with the improved models of the various missiles.

In the case of a manned flight to the moon, one of the first missions proposed for a ROVER-type nuclear rocket, a reasonably high reliability factor becomes mandatory, considering the enormous cost of the undertaking and the necessity to protect the lives of the astronauts piloting the mission.

The nuclear-rocket stage is but one component in a complex system for the lunar mission, and hence it is important that it have a high probability of proper functioning during the mission. This reliability must be established by a series of tests of the rocket engine and/or rocket-engine components in final flight configuration. To the extent that the operating environment of the rocket engine can be simulated on earth, the tests can be performed on the ground. This is desirable, since flight testing of a rocket engine in space is many times more difficult and expensive than ground testing. In any event, it is necessary to minimize the number and duration of the full-scale rocket engine tests consistent with the desired reliability.

The calculations presented here are directed toward determining the number and duration of full-scale rocket-engine tests necessary to assure a given rocket-motor core reliability at various confidence levels. The basis for the calculations is a hypothetical mission of one-hour duration.

1. Reliability Criteria

a. Definition of Reliability

Reliability $R$, expressed as a fraction from 0 to 1 , states the probability of success, that is, $R=0.95$ means 95 successes and 5 failures out of 100 trials. This may also be stated in terms of the fundamental definition of probability. The probability of an event $A$ is defined as the fractional relationship between the number of favorable trials of event $A$ and the total number of trials, with the stipulation that each trial has an equal chance to result in the event $A$. Thus, when each trial ends either favorably (event A) or unfavorably (event B), and there are $X$ number of trials leading to event $A$ and $Y$ number of trials to event $B$, the total number of trials is $X+Y$ and the probability $P$ of event $A$ is 


$$
P(A)=\frac{X}{X+Y} .
$$

Also, the probability of event $B$ will be defined as

$$
P(B)=\frac{Y}{X+Y} \text {. }
$$

Since the exact value of a probability requires an infinite number of trials, we are only dealing with an estimate of the true probability. Thus, the larger the number of trials the closer the estimate will be.

For example, in the act of flipping an honest coin one can state a priori that the probability of obtaining a head on a given toss of the coin is the same as the probability of obtaining a tail. The probability for either is 0.5. However, in 100 trials one may obtain a head 45 times and a tail 55 times; hence, the estimated probability obtaining a head from the se trials is 0.45 . This estimate will approach 0.5 as the number of trials increases.

In dealing with the probabilities of failure or nonfailure in an operating system, it can be shown that the probability of failure within a certain time interval from 0 to $t$ is given by the area under the failure density curve for that time interval, or

$$
Q(t)=\int_{0}^{t} f(t) d t
$$

where

$$
\begin{aligned}
& f(t) \text { is the failure density function, } \\
& Q(t)=\text { probability of failure or unreliability. }
\end{aligned}
$$

This area increases for the longer operating time $t$, and therefore the probability of failure increases with $t$. Conversely, the probability of survival decreases for longer operating times.

$$
\begin{aligned}
& \text { Since } R=1-Q, \\
& R(t)=1-\int_{0}^{t} f(t) d t,
\end{aligned}
$$

where

$R(t)=$ probability of survival or reliability. 
Since the area under the density curve is always unity, i.e.,

$$
\int_{0}^{\infty} f(t) d t=1
$$

we can write

$$
R(t)=\int_{0}^{\infty} f(t) d t-\int_{0}^{t} f(t) d t=\int_{t}^{\infty} f(t) d t
$$

which means that the probability of survival decreases as the remaining area under the density curve decreases. Equation (A-2) describes the reliability in terms of a generalized failure density curve and, hence, the reliability for any operating time can be calculated if $f(t)$ is known.

\section{b. Modes of Failure}

In order to determine the mathematical form for $f(t)$, it is necessary to know something about the mode of failure of the system. Figure A-l shows the typical failure behavior of a component or a system as a function of the age or operating time. As shown, there are three

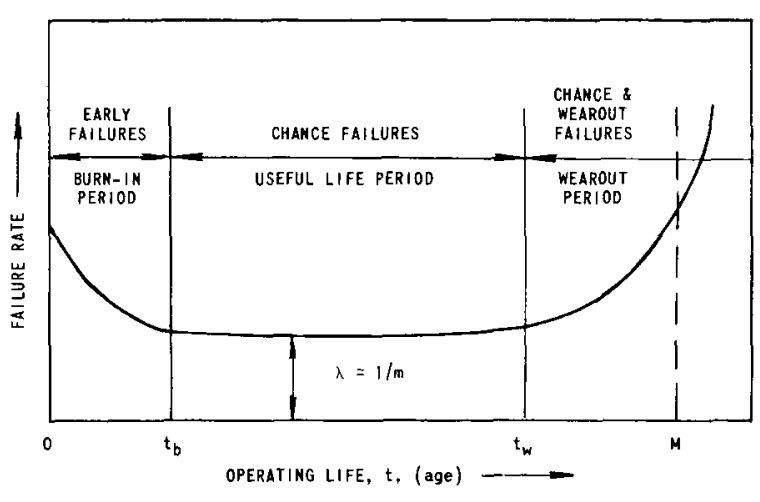

I $12-4008$

Fig. A-1. Failure Rate Versus Lifetime for an Operating System characteristic failure regimes during the lifetime.

At time $t=0$ we place in operation a large number of components of a certain kind. The population will initially exhibit a very high failure rate if it contains some portion of substandard, weak specimens. As these weak components fail one by one, the failure rate decreases comparatively rapidly during the so-called "burn-in" or "debugging" period and stabilizes to an approximately constant value at the time $t_{b}$ when the weak components have died out. At this time the population has its lowest failure rate, and this low rate continues at an approximately constant value throughout the so-called useful life or chance failure period. When the components reach the time $t_{w}$, wearout begins to become noticeable, and from that time on the failure rate increases rapidly. From this it can be seen that to obtain a high reliability we should be sure that the desired life of the component does not extend beyond the time $t_{W}$ and hence wearout failures will not 
occur during the desired operating time. Furthermore, one must be sure that the chance failure rate is at a low enough value to be acceptable and that the early failures have been eliminated.

\section{(1) Early Failures}

The common way to eliminate the early failures is by means of an initial de-bugging or burn-in period of short duration in which the components are all operated at design conditions. The substandard components fail and are eliminated. This technique is important in the case of manufacturing a large number of components, during which only a fraction of the components are inspected and in which some compromises in tolerance are necessary to achieve the large quantity production.

In the case of relatively limited-quantity, custom-built items like a nuclear-powered rocket engine, the potential early failures can perhaps be eliminated by a very rigid tolerance and through inspection methods. It is undoubtedly possible to bench test certain components of the rocket engine, such as various pumps and control devices, to achieve this same end. It is not, however, practical to use this technique on the components of the core because of the complications in handling the radioactive core which would result. Therefore, the inspection techniques must be utilized to weed out potential early failures among the core components.

\section{(2) Chance Failures}

The stresses acting on components fall in two main categories (from Ref. 5): (a) Environmental stresses are present whether a component in a system is actively operating or is in a state of quiescence. Humidity, atmospheric pressure, radiation, chemical content, and impurities of the atmosphere and environmental temperature at the place where the component is located are possible causes of environmental stresses. These stresses normally do not cause chance failures of quiescent components, but may cause a deterioration of component strength under prolonged contact. If the quiescent component is in an operating system, it may be exposed to mechanical stresses such as vibration, shock, and acceleration. These stresses are still environmental stresses which act on the component whether it is in operation or not, but they differ from the other environmental stresses in that they can cause chance failure as well as gradual fatigue and deterioration. (b) Operating stresses appear only when the component is in active operation. The passage of electrical current, self-generation of heat, and the performance of mechanical motions are examples of the causes of operating stresses. These normally lead to chance failure, but at the same time they also contribute significantly to component strength deterioration which leads to wearout. 
Figure A-2 shows a diagrammatic representation of the situation occurring with regard to chance failure of a component during its useful life. The jagged line represents the stress spectrum to which the component is subjected. The horizontal lines represent the different strength levels of components. As can be seen, the chance failures will occur in component of strength $s_{2}$ frequently since the stress exceeds its strength frequently. A component of strength $s_{1}$, on the other hand, will survive chance failure for much longer time and finally fail when its strength begins to deteriorate due to wearout.

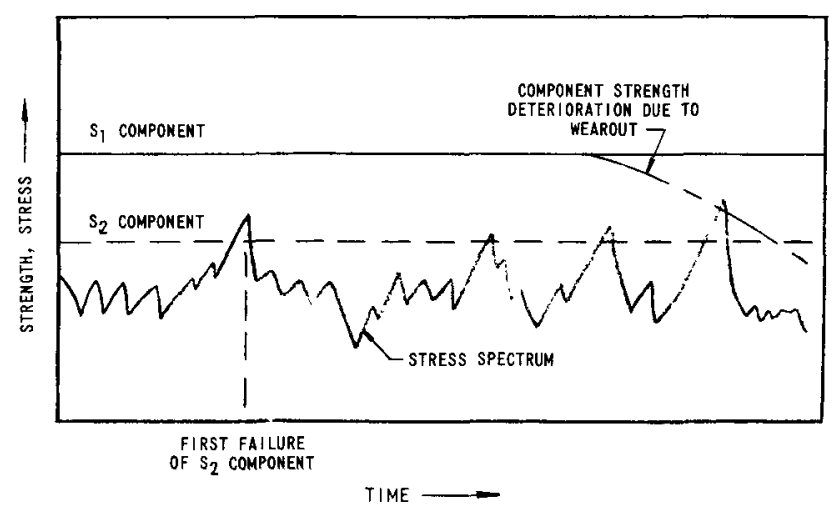

$112-4004$

Fig. A-2. Stress Spectrum for a Component during Its Useful Life Period

The failure density distribution for the useful life, or constant failure rate, of the component is given by an exponential with the parameter $\lambda=1 / \mathrm{m}$ determining the characteristic curve for a given mean time between failures, $m$. The equation for the distribution is

$$
f(t)=\lambda e^{-\lambda t}
$$

Thus the distribution of chance failures during the useful life of a component is a one-parameter distribution and is completely determined by $m$. The reliability or probability of survival until time $t$ is then the area under the curve from $t$ to infinity as given by Eq. $(A-2)$. When $f(t)$ is given by Eq. $(\mathrm{A}-3)$,

$$
\left.R_{C}(t)=\int_{t}^{\infty} \lambda e^{-\lambda t} d t=-e^{-\lambda t}\right]_{t}^{\infty}=e^{-\lambda t} .
$$

The reliability function $R_{c}(t)$ is shown in Fig. A-3. 


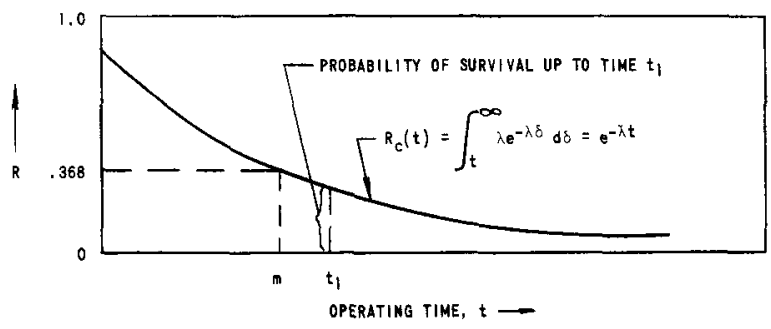

(a) CHANCE FAILURE INTEgRAL

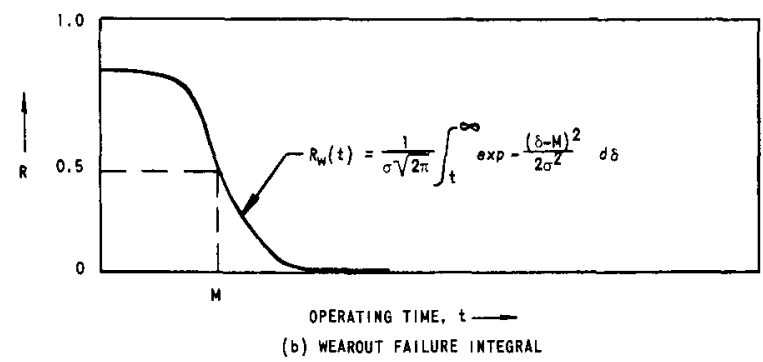

Fig. A-3

Reliability Curves

$112-3992$

\section{(3) Wearout Failures}

In most cases wearout displays the typical characteristics of a normal or Gaussian distribution. The Gaussian normal failure density curve is given by

$$
f(t)=\frac{1}{\sigma \sqrt{2 \pi}} \exp \left[-(t-M)^{2} / 2 \sigma^{2}\right],
$$

where $M$ is the mean wearout life, $t$ is the age or accumulated operating time since new, and $\sigma$ is the standard deviation of the lifetimes from the mean $M$, defined as

$$
\sigma=\sqrt{\frac{\sum(t-M)^{2}}{n}}
$$

where $\mathrm{n}$ is the sample size. The integral of this distribution is shown in Fig. A-3. Here again the area under the curve from the time $t$ to infinity gives the reliability or probability of survival up to time $t$. In contrast with the chance failure distribution, the wearout failure distribution is a curve determined by two parameters instead of one, namely, $M$ and $\sigma$. For reliability calculations the areas under a standardized normal density curve are obtained from handbooks of statistical tables. $(6,7)$ It is necessary to determine $M$ and $\sigma$ for the population of components under test experimentally. With these values it is then possible to calculate the reliability or probability of surviving wearout for a given operating time. 
(4) Combined Effect of Chance and Wearout Failure

The overall reliability of a system or component for an operating time $t$ is given by the product of the probabilities of surviving chance failure and wearout failure. This is shown graphically in Fig. A-4.

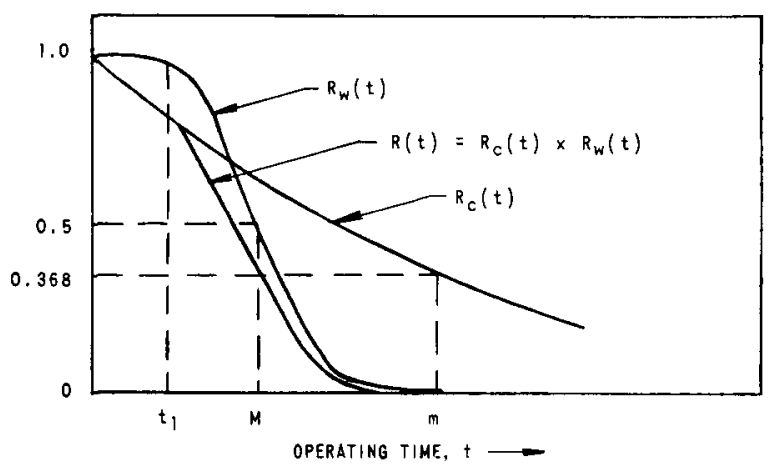

$112-4001$ The individual curves labeled $R_{C}(t)$ and $R_{W}(t)$ in the figure are the integrated failure density curves for the chance and wearout failure, respectively (see Fig. A-3). The third curve, labeled $R(t)$, represents the overall survival probability. The transition from exponential behavior to the wearout behavior (at $t_{1}$ ) occurs for a component generally at an age between $M-3.5 \sigma$ and $M-3 \sigma$. For lower ages ( $M-4 \sigma$ and less), the probability of wearout failure is insignificant for a single component. The chance and wearout failure reliability curve shown in Fig. A-4 shows a behavior which is typical of most components, that is, $\mathrm{m}$ is greater than $\mathrm{M}$.

The general approach used in attaining high reliability is to overhaul or remove a component from service at an age of $\mathrm{M}-3 \sigma$ or thereabouts, and thereby as sure that very few components will fail because of wearout. If the chance failure rate is low, then this procedure will assure a high reliability.

\section{c. Duplication of Environment in Testing}

An obvious first requirement for any testing program to es tablish system or component reliability is that the environment during the test be exactly that which will be encountered in operation. This implies that the critical or stress-producing environmental factors be duplicated in testing. When it is possible to state with assurance that an environmental condition is not critical, then it need not be duplicated during testing. In most test programs, however, the ignorance factor is large, and it becomes necessary to attempt to duplicate operating conditions as closely as possible.

Testing programs can be speeded up to a certain degree by using so-called accelerated test methods. This merely means that the components are subjected to more severe conditions than are anticipated during operation. Under these conditions the failure rate under test will be higher. This procedure gives statistically useful information in a shorter time period, but suffers from difficulty in translating the test data 
into failure rates under actual operating conditions. In testing equipment which is operating very close to the limit of its capability, i.e., such that a slight increase in stress levels would produce catastrophic failure almost immediately, this procedure is of little use. The inverse of accelerated testing, namely, a derating of components in actual operation, produces lower failure rates and is one of the more commonly used methods of increasing system and component reliability.

\section{d. Point Estimates Versus Confidence Limits}

The estimates of the mean time between failures, $m$, mean wearout life $M$, and the standard deviation $\sigma$, obtained by measurements as discussed above are so-called point estimates of the true unknown parameters. Since statistical estimates are more likely to be close to the true value as the sample size increases, there is a close correlation between the accuracy of an estimate and the size of the sample from which it was drawn. Only an infinitely large sample size would give $100 \%$ confidence or certainty that a measured statistical parameter coincides with the true value. In this sense "confidence" is a mathematical probability relating to mutual positions of the true value of a parameter and its estimate.

Confidence intervals around the point estimate consist of a lower confidence limit $L$, and upper confidence limit $U$. For example, a $90 \%$ confidence level means that in $90 \%$ of the cases the true value will lie within these limits, whereas in $10 \%$ of the cases it will be outside the limits. If we wish to increase the confidence level to, say, 99\%, the confidence interval around the point estimate would have to become larger or else we have to use a larger sample for the point estimate to retain the same confidence limits at the higher level of confidence. Thus, for a given confidence level, either the number of measurements or the confidence limits are determined. Generally speaking, in the reliability analyses a confidence level of 75 to $95 \%$ is used as this is the most satisfactory range from the viewpoint of a reasonably high insurance of reliability versus the amount of test data required.

\section{Calculations of Rocket Engine Reliability}

\section{a. Chance Failures}

As shown in Ref. 5, the minimum time between failures, $C_{L}$, for a given confidence level is given by the formula

$$
\mathrm{C}_{\mathrm{L}}=2 \mathrm{~T} / \chi_{\alpha ; 2 \mathrm{r}+2}^{2}
$$

where $T$ is the accumulated test time, $\chi_{\alpha ; 2 r+2}^{2}$ is the tail area under the chi-squared distribution curve for a specified confidence level of $100(1-\alpha)$, and $r$ is the number of failures observed. 
This is the so-called one-sided confidence interval and assures that $m$ will be greater than the required value, $C_{L}$, with the confidence of $100(1-\alpha)$ per cent. The probability of survival from chance failure is given by the area under the exponential failure distribution curve, and the value of $m$ to achieve a reliability $R_{C}(t)$ for an operating time $t$ is given by [from Eq. $(\mathrm{A}-4)$ ]

$$
m=\frac{t}{\ln R_{C}(t)}
$$

Combination of Eqs. $(A-7)$ and $(A-8)$, since $m=C_{L}$, gives the following equation for the number of minutes of testing required per operational minute $(T / t)$ at the given confidence level and reliability value desired:

$$
\frac{\mathrm{T}}{\mathrm{t}}=\frac{\chi_{\alpha ; 2 \mathrm{r}+2}^{2}}{-2 \ln \mathrm{R}_{\mathrm{C}}(\mathrm{t})}
$$

There is no restriction on the number of individual tests performed. The important parameter given by Eq. $(A-9)$ is the total accumulated test time. Thus the actual lapsed test time can be considerably less than the required mean time between failures, $m$, by testing a large number of specimens simultaneously. Of course, in general, it is necessary to be sure that there are some tests longer than the required operation time to be sure that the wearout failures will not occur during the desired useful lifetime. Values of the required time units of testing per operational unit, $\mathrm{T} / \mathrm{t}$, were calculated by Eq. (A-9), and plotted in Figs. A-5 and A-6 for reliabilities of $0.80,0.90,0.95$, and 0.99 at confidence levels of $70,80,90$, and $95 \%$. As shown, the required amount of testing is very large to assure reliability against chance failure of 0.99 and is greatly reduced for a reliability of 0.95 at the same confidence level.

These results are interpreted as follows. If a nuclear rocket reactor is to perform at design conditions for a time of one hour and have a reliability of surviving chance failure of 0.95 at a confidence level of $90 \%$, then about $45 \mathrm{hr}$ of total operational time with no failures must be accumulated. If one failure is observed, the total time is increased to about $75 \mathrm{hr}$; if two are observed, the total time is $103 \mathrm{hr}$, and so on. If the confidence level is reduced to $70 \%$, then the corresponding test times are 23,47 , and $70 \mathrm{hr}$ for 0,1 , and 2 observed failures. As stated, this total operating time can be accumulated on any number of specimens so long as none of them operate long enough so that wearout failures start to occur. 


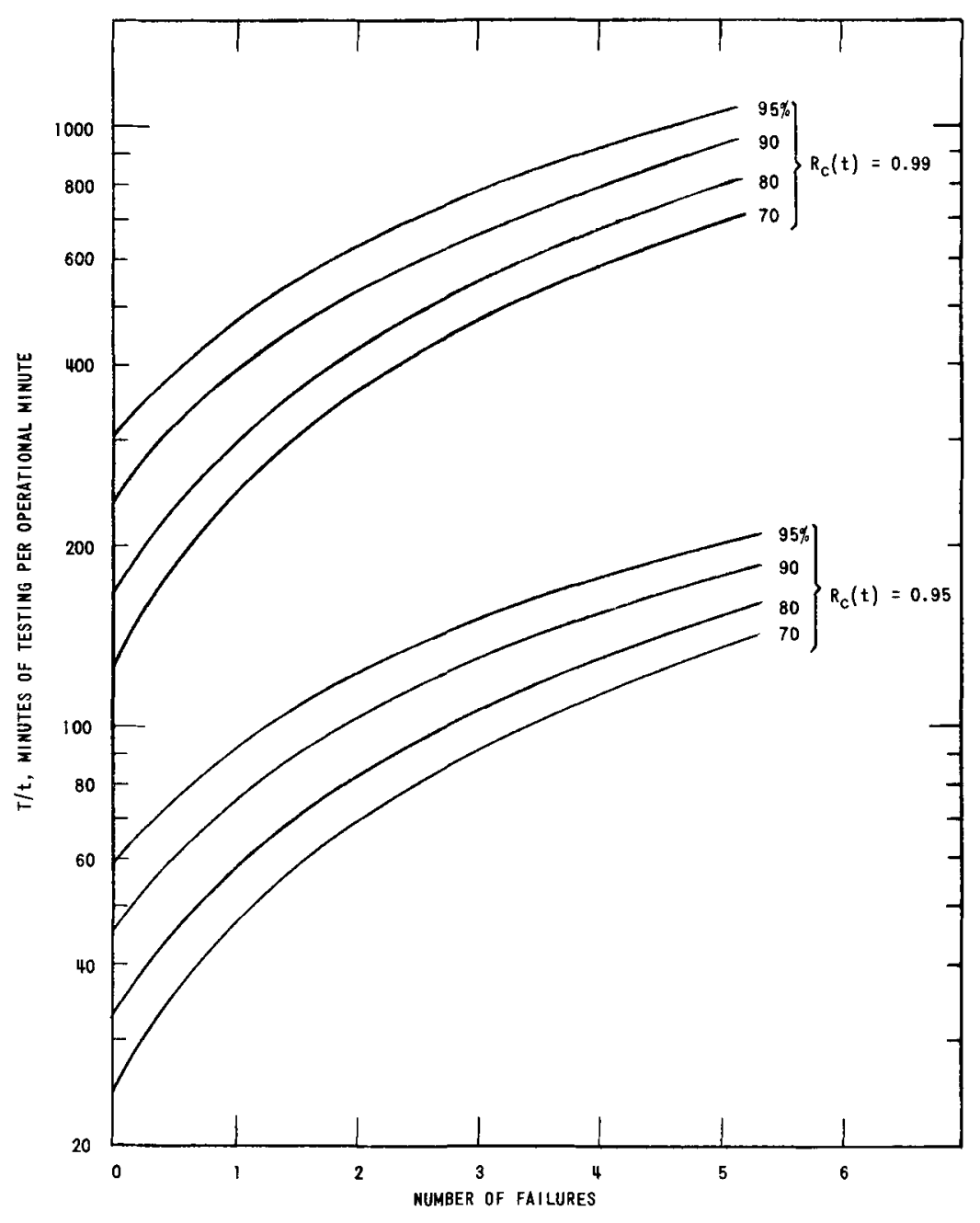

$112-4000$

Fig. A -5. Minutes of Testing per Operational Minute for Chance Failure Reliabilities of 0.99 and 0.95 at Various Confidence Levels

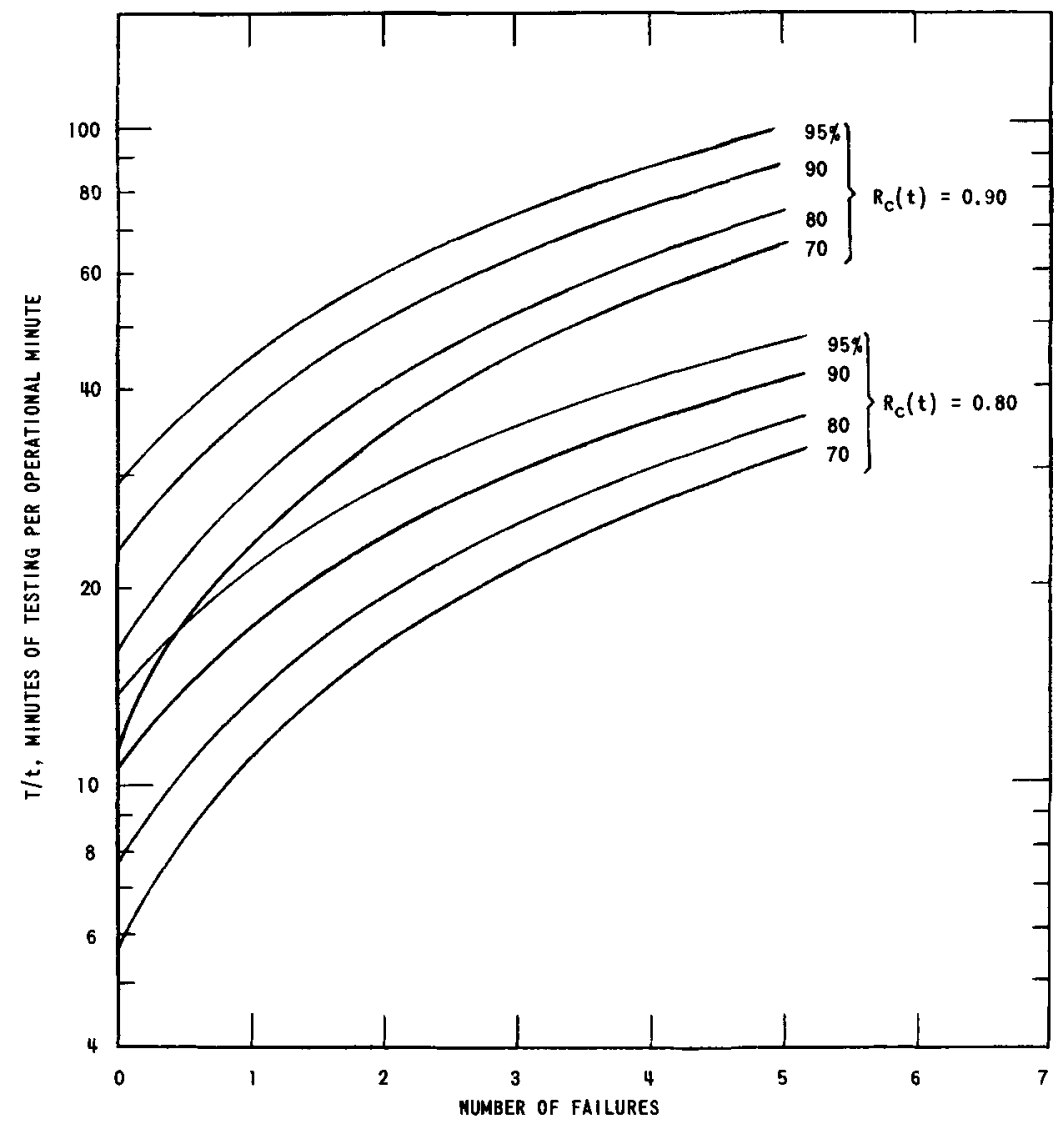

$112-3999$

Fig. A-6. Minutes of Testing per Operational Minute for Chance Failure Reliabilities of 0.90 and 0.80 at Various Confidence Levels 


\section{b. Wearout Failures}

As shown in Fig. A-4, the probability of surviving both chance and wearout failure up to a given time $t$ is the product $R_{C}(t) R_{W}(t)$. Hence, it is also necessary to know something about the mean time to failure, $M$, and its standard deviation in order to define completely the reliability of a component or a system for an operating time $t$. Since the wearout failure distribution is a normal or two-parameter distribution curve, it is necessary therefore to have at least two measurements of the mean time to failure, $M$. Estimates of $M$ and $\sigma$ can be obtained from any number of wearout failures from two upward. Obviously, the greater the number of measurements of observed wearout failures, the closer will be the estimates of $\mathrm{M}$ and $\sigma$.

The lower one-sided confidence limit $L$ for the normal distribution is given (see Ref. 5) by

$$
L=\hat{M}-K_{\alpha} \sigma / \sqrt{n} \text {, }
$$

where $\hat{\mathrm{M}}$ is the estimate of $\mathrm{M}$ obtained from $\mathrm{n}$ failures, and $\mathrm{K}_{\alpha}$ is the number of standard deviations required to obtain the lower confidence limit for a required confidence level of $100(1-\alpha)$.

In Eq. $(A-10) \sigma$ is usually replaced by $s$, where $s$ is the estimate of the population standard deviation based on the measurements of the $n$ samples and is given by

$$
s=\sqrt{\frac{\sum(t-\hat{M})^{2}}{n-1}} .
$$

The actual standard deviation of the component life is given by Eq. (A-6). Thus the estimate for $\sigma$ given by Eq. (A-11) will be very close to the true value of $\sigma$ given by Eq. $(A-6)$ as $n$ increases, and for large $n$ the two will be identical.

The above equations for the lower confidence limit $L$ and the estimate of the standard deviation $s$, however, are only applicable and accurate for sample sizes greater than $\approx 25$. For $n<25$, i.e., small sample sizes, a normal distribution of the small-sample measurements can no longer be assumed, since in general a small sample will contain fewer extreme members than the population as a whole. Allowance for this fact is made by using Student's "t distribution" correlation for the data from a small number of samples. As shown in Ref. 5, the lower confidence limit for the small-sample analysis is obtained by replacing $\mathrm{K}_{\alpha}$ in Eq. $(\mathrm{A}-10)$ with $\mathrm{t}_{\alpha ; \mathrm{n}-1}$ and by replacing $\sigma$ with $\mathrm{s}$. Thus, the lower confidence limit based on the small-sample analysis is given by the equation 


$$
L_{s}=\hat{M}-t_{\alpha ; n-1} \frac{s}{\sqrt{n}} \text {. }
$$

Furthermore, in this case $s \approx \sigma$ cannot be assumed, and the data can only give an upper bound for $s$. This upper bound for the standard deviation is

$$
S_{u}=s \sqrt{\frac{n-1}{x_{1-\alpha ; n-1}^{2}}},
$$

where $S_{u}$ is the upper limit of $s$ at a confidence level of $100(1-\alpha)$. The values for $t_{\alpha ; n-1}$ and $\chi_{1-\alpha ; n-1}^{2}$ are given in the handbooks of statistical tables. $(6,7)$

In order to attain a given reliability against wearout failure, it is necessary to be sure that the mission duration or desired lifetime does not extend appreciably into the left-hand tail of the normal wearout distribution curve. This leads to the concept of a replacement or overhaul time $t_{0}$ as given by the following equation for normally distributed or large-sample data:

$$
t_{0}=L-k \sigma,
$$

where $k$ is the number of standard deviations to the left of $L$ required for a given reliability $R_{\mathrm{W}}(t)$. Further,

$$
t_{0}=L_{s}-k S_{u}
$$

for the small-sample data which obeys Student's "t distribution." By combining Eqs. (A-12), (A-13), and (A-15), we obtain the following equation for the mission duration or operating time before overhaul;

$$
t_{0}=\hat{M}-t_{\alpha ; n-1} \frac{s}{\sqrt{n}}-k s \sqrt{\frac{n-1}{\chi_{1-\alpha ; n-1}^{2}}} .
$$

As a convenience, let

$$
\mathrm{s}=\mathrm{x \hat {M }}
$$

Then the equation can be written as

$$
\frac{t_{0}}{\hat{M}}=1-t_{\alpha ; n-1} \frac{x}{\sqrt{n}}-k x \sqrt{\frac{n-1}{\chi_{1-\alpha ; n-1}^{2}}} .
$$

The substitution $s=x \hat{M}$ is merely a way of expressing the unknown standard deviation in terms of the estimated mean wearout time $\mathrm{M}$. 
Eq. (A-16) is normalized in terms of the mission duration $t_{0}$ and gives the ratio of the mission duration to the estimated mean wearout time from observation of $\mathrm{n}$ sample wearout failures. For longer missions it is only necessary to multiply the value of $\widehat{M}$ given by Eq. (A-16) by the required mission duration $t_{0}$. The total testing time is given by Mn hours per hour of required mission time.

Equation $(A-16)$ was used to solve for $\widehat{M}$, assuming required wearout reliabilities of 0.95 and 0.99 , and values of 0.10 and 0.20 for $\mathbf{x}$. The results of the calculations, in each case done for assumed confidence levels of $70,80,90$, and $95 \%$, are given in Table A-1. The blank spaces in the table, in some cases, for the fewer number of tests arise from the difficulty of using the normal distribution when $\widehat{M}<3 \sigma$, since under this condition the left-hand tail of the normal distribution extends to negative time values. When this situation arises, it is recommended that the log normal distribution be used. (5)

Table A-1

RESULTS OF WEAROUT RELIABILITY CALCULATIONS

\begin{tabular}{|c|c|c|c|c|c|c|c|c|c|c|c|c|c|c|c|c|c|}
\hline \multirow{3}{*}{$\frac{x}{n}$} & \multicolumn{4}{|c|}{ 95\% Confidence } & \multicolumn{4}{|c|}{$90 \%$ Confidence } & \multicolumn{4}{|c|}{$80 \%$ Confidence } & \multicolumn{4}{|c|}{$70 \%$ Confidence } & \multirow{3}{*}{$\frac{x}{n}$} \\
\hline & \multicolumn{2}{|c|}{010} & \multicolumn{2}{|c|}{020} & \multicolumn{2}{|c|}{010} & \multicolumn{2}{|c|}{020} & \multicolumn{2}{|c|}{010} & \multicolumn{2}{|c|}{020} & \multicolumn{2}{|c|}{010} & \multicolumn{2}{|c|}{020} & \\
\hline & $\hat{M}$ & $\widehat{M} n$ & $\widehat{M}$ & $\widehat{M}_{n}$ & $\widehat{M}$ & $\widehat{M}_{n}$ & $\widehat{M}$ & $\widehat{M n}$ & $\widehat{M}$ & $\widehat{M} \mathrm{n}$ & $\widehat{M}$ & $\widehat{M} \mathrm{n}$ & $\hat{M}$ & $\hat{M} n$ & $\widehat{M}$ & $\widehat{M n}$ & \\
\hline \multicolumn{18}{|c|}{ A Wearout Reliability, $R_{w}(t)-095$} \\
\hline 2 & - & - & - & - & - & - & - & - & $4 \underline{0}$ & 80 & - & - & 19 & $\underline{38}$ & 217 & 434 & 2 \\
\hline 3 & 104 & 312 & - & - & 26 & 78 & - & - & $\overline{17}$ & 51 & 55 & 165 & $\overline{15}$ & $\overline{45}$ & 27 & $\underline{81}$ & 3 \\
\hline 4 & 25 & 100 & - & - & $\overline{18}$ & 72 & 116 & 464 & 15 & $\overline{60}$ & 30 & 120 & 14 & 56 & $\overline{22}$ & $\overline{88}$ & 4 \\
\hline 5 & $\overline{19}$ & 95 & 357 & 179 & 16 & $\overline{80}$ & 46 & 230 & 14 & 70 & $\overline{25}$ & $\overline{125}$ & 13 & 65 & 20 & 100 & 5 \\
\hline 6 & 17 & $\overline{102}$ & 68 & 408 & 15 & 90 & $\overline{33}$ & 198 & 14 & 84 & 23 & 138 & 13 & 78 & 19 & 114 & 6 \\
\hline 7 & 16 & 112 & 45 & 315 & 15 & 105 & 29 & $\underline{203}$ & 14 & 98 & 21 & 147 & 13 & 91 & 18 & 126 & 7 \\
\hline 8 & 16 & 128 & $\overline{36}$ & $\underline{288}$ & 14 & 112 & 26 & 208 & 13 & 104 & 20 & 160 & 13 & 104 & 18 & 144 & 8 \\
\hline 9 & 15 & 135 & 32 & $\overline{288}$ & 14 & 126 & 24 & 216 & 13 & 117 & 20 & 180 & 13 & 117 & 18 & 162 & 9 \\
\hline 10 & 15 & 150 & 29 & 290 & 14 & 140 & 23 & 230 & 13 & 130 & 19 & 190 & 13 & 130 & 17 & 170 & 10 \\
\hline 20 & 14 & 280 & 21 & 420 & 13 & 260 & 19 & 380 & 13 & 260 & 17 & 340 & 12 & 240 & 16 & 320 & 20 \\
\hline \multicolumn{18}{|c|}{ B Wearout Relıabilıty, $R_{W}(t) \quad 099$} \\
\hline 2 & - & - & - & & & - & - & - & - & - & - & - & $\underline{29}$ & 58 & & - & 2 \\
\hline 3 & - & - & - & - & 59 & 177 & - & - & $2 \underline{2}$ & $\underline{66}$ & - & - & 17 & 51 & 68 & 204 & 3 \\
\hline 4 & 50 & 200 & - & - & 26 & 104 & - & - & $\overline{18}$ & $\overline{72}$ & 104 & 416 & 16 & $\overline{64}$ & 38 & 152 & 4 \\
\hline 5 & $\overline{28}$ & 140 & & - & $\overline{21}$ & 105 & - & & 17 & 85 & 53 & 265 & 15 & 75 & $\sqrt{31}$ & $\overline{155}$ & 5 \\
\hline 6 & 23 & 138 & - & - & 19 & 114 & 167 & 100 & 16 & 96 & 46 & 276 & 15 & 90 & 28 & 168 & 6 \\
\hline 7 & 21 & $\overline{147}$ & - & - & 18 & 126 & 82 & 574 & 16 & 112 & 36 & 252 & 15 & 105 & 27 & 189 & 7 \\
\hline 8 & 19 & 152 & 312 & 250 & 17 & 136 & 60 & 480 & 15 & 120 & 32 & $\overline{256}$ & 14 & 112 & 26 & 208 & 8 \\
\hline 9 & 19 & 171 & 127 & 1143 & 17 & 153 & 49 & 440 & 15 & 135 & 31 & 279 & 14 & 126 & 25 & 225 & 9 \\
\hline 10 & 18 & 180 & 87 & 870 & 16 & 160 & $\overline{44}$ & $\overline{440}$ & 15 & 150 & 29 & 200 & 14 & 140 & 24 & 240 & 10 \\
\hline 12 & 17 & 204 & 57 & 684 & 16 & 192 & 37 & 444 & 15 & 180 & 27 & 324 & 14 & 168 & 23 & 276 & 12 \\
\hline 14 & 16 & 224 & 46 & 644 & 15 & 210 & 34 & 476 & 15 & 210 & 26 & 364 & 14 & 196 & 23 & 322 & 14 \\
\hline 16 & 16 & 256 & $\overline{41}$ & 656 & 15 & 240 & 31 & 496 & 14 & 224 & 25 & 400 & 14 & 224 & 22 & 352 & 16 \\
\hline 18 & 16 & 288 & 38 & 684 & 15 & 270 & 30 & 540 & 14 & 252 & 25 & 450 & 14 & 252 & 22 & 396 & 18 \\
\hline 20 & 15 & 300 & 35 & 700 & 15 & 300 & 29 & 580 & 14 & 280 & 24 & 480 & 14 & 280 & 22 & 440 & 20 \\
\hline
\end{tabular}

In interpreting the se results it was arbitrarily assumed that a successful rocket engine having the capability for performing a one-hour mission with a high probability of success would probably not have a wearout life greater than $5 \mathrm{hr}$. With this criterion as a guide, it is possible to select from the results presented in the table the minimum number of tests required for a given set of conditions. This minimum is underlined for each case. 
The product $\hat{\mathrm{M}}$ gives the total testing time required. As shown, the minimum time frequently corresponds to the minimum number of tests, and in all cases it is not greatly different from the value for the minimum number of tests. From these results it is concluded that the most economical method of testing is to conduct the minimum number of tests. The only advantage of going to a larger number of tests is that there is a reduction in the required time to wearout; however, this change is small after 6 to 8 tests for most cases.

From these results and those given in Figs. A-5 and A-6, it is also seen that the testing required to assure a given wearout reliability is less than that required to assure a given chance failure reliability. For example, if we desire a system wearout reliability of 0.99 for a one-hour mission at a $90 \%$ confidence level, the minimum testing time (from Table A-1) is obtained with 9 tests, giving an average wearout time $\hat{\mathrm{M}}$ of $4.9 \mathrm{hr}$ and a total testing time of $44 \mathrm{hr}$ with a standard deviation of $\pm 20 \%$. If the standard deviation is only $\pm 10 \%$, then the number of tests is reduced to 4 having an average $M$ of $2.6 \mathrm{hr}$ and a total test time of $10.4 \mathrm{hr}$. Since the standard deviation as well as the wearout time cannot be determined without some tests, the scope of the testing program can only be estimated after some tests have been run.

If a total of $44 \mathrm{hr}$ of testing for a standard deviation of $\pm 20 \%$ are accumulated with 9 wearout failures having $\hat{\mathrm{M}}=4.9$, the reliability is 0.99 at $90 \%$ confidence for a one-hour mission. Furthermore, these tests do give an indication of the chance failure reliability. From Fig. A-5 it is seen that $44 \mathrm{hr}$ with no chance failures assures a chance failure reliability of 0.95 at a $90 \%$ confidence level. Thus the overall system reliability against chance and wearout failure is $0.99 \times 0.95=0.94$ at a $90 \%$ confidence level.

Other examples can be worked similarly. In using these results it is recommended that a confidence level of $90 \%$ be used because this is the level specified in military contracts having numerical reliability requirements.

\section{c. Reliability of Series Systems}

An alternative to testing complete systems is to test the system components individually. If all the components form a series reliability model with no redundant components (failure of a single component causes system failure), then the reliability of the system, $R_{S}$, is given by the product of the individual component reliabilities, that is,

$$
R_{S}=R_{1} R_{2} R_{3} \ldots R_{n}=\prod_{i=1}^{n} R_{i}
$$


The individual component reliabilities were calculated by means of the same equations developed in the previous sections.

Consideration is given here to a rocket-engine core with 1000 fuel elements. If the useful life period (or mission duration) of a single element is $M-4 \sigma$, then its wearout failure reliability is 0.99997 . With 1000 of these elements in a series dependence, the overall core reliability is

$$
R_{W}(t)=(0.99997)^{1000}=0.97 .
$$

Since it is feasible to run a much larger number of tests on single fuel elements, the number can be greater than 25 . Then $s \approx \sigma$ can be assumed, and small-sample statistics are no longer necessary. By means of this approach, calculations were done for a reliability of 0.99997 , using Eqs. (A-10) and (A-14). The results of these calculations for confidence levels of $70,80,90$, and $95 \%$ a re given in Table A-2. As shown by the results, the mean failure time $\hat{M}$ is less sensitive to the confidence level than in the small-sample results given in Table A-l. This occurs because the true value of $M$ and $\sigma$ for a normally distributed population is determined with rapidly increasing accuracy as $n$ increases above 25 . Thus the uncertainty factor, as sociated with confidence level, becomes less important.

Table A-2

RESULTS OF WEAROUT RELIABILITY CALCULATIONS FOR AN INDIVIDUAL COMPONENT RELIABILITY OF 0.99997

\begin{tabular}{|c|c|c|c|c|c|c|c|c|c|}
\hline $\mathrm{x}$ & \multicolumn{2}{|c|}{0.10} & \multicolumn{2}{|c|}{0.20} & \multicolumn{2}{|c|}{0.10} & \multicolumn{2}{|c|}{0.20} & \multirow{2}{*}{$\frac{\mathrm{x}}{\mathrm{n}}$} \\
\hline $\mathrm{n}$ & $\widehat{\mathrm{M}^{*}}$ & $\widehat{\mathrm{Mn}}$ & $\widehat{\mathrm{M}}$ & $\widehat{\mathrm{Mn}}$ & $\widehat{\mathrm{M}}$ & $\widehat{\mathrm{M}_{n}}$ & $\widehat{\mathrm{M}}$ & $\widehat{\mathrm{Mn}}$ & \\
\hline \multicolumn{5}{|c|}{ A. Confidence $=95 \%$} & \multicolumn{5}{|c|}{ B. Confidence $=90 \%$} \\
\hline 26 & 1.7 & 45 & 6.5 & 168 & 1.7 & 45 & 6.7 & 174 & 26 \\
\hline 28 & . & 48 & 6.4 & 179 & 1 & 49 & 6.6 & 185 & 28 \\
\hline 30 & & 52 & 6.3 & 190 & & 52 & 6.5 & 196 & 30 \\
\hline 32 & & 55 & 6.3 & 201 & & 55 & 6.5 & 207 & 32 \\
\hline 34 & & 59 & 6.2 & 212 & & 59 & 6.4 & 218 & 34 \\
\hline 36 & & 62 & 6.2 & 222 & & 62 & 6.4 & 229 & 36 \\
\hline 38 & & 65 & 6.2 & 234 & & 66 & 6.3 & 240 & 38 \\
\hline 40 & $\downarrow$ & 69 & 6.1 & 244 & $\downarrow$ & 69 & 6.3 & 251 & 40 \\
\hline \multicolumn{5}{|c|}{ C. Confidence $=80 \%$} & \multicolumn{5}{|c|}{ D. Confidence $=70 \%$} \\
\hline 26 & 1.7 & 45 & 6.0 & 156 & 1.7 & 44 & 5.6 & 145 & 26 \\
\hline 28 & & 48 & 6.0 & 168 & . & 47 & 5.6 & 155 & 28 \\
\hline 30 & & 51 & 5.9 & 177 & & 51 & 5.5 & 166 & 30 \\
\hline 32 & & 55 & 5.9 & 189 & & 54 & 5.5 & 176 & 32 \\
\hline 34 & & 58 & 5.8 & 197 & & 58 & 5.5 & 187 & 34 \\
\hline 36 & & 62 & 5.8 & 209 & & 61 & 5.5 & 197 & 36 \\
\hline 38 & & 65 & 5.8 & 220 & & 64 & 5.5 & 207 & 38 \\
\hline 40 & $\downarrow$ & 68 & 5.8 & 232 & $\downarrow$ & 68 & 5.5 & 218 & 40 \\
\hline
\end{tabular}

*For definitions of symbols, see Table A-I. 
The following example illustrates the use of Table A-2. If 30 single-element tests are run, resulting in a mean failure time of $6.5 \mathrm{hr}$ and a standard deviation of $\pm 20 \%$, then $R_{W}(t)=0.99997$ for the single fuel element and $R_{W}(t)=0.97$ for a core containing 1000 elements. The total test time is $196 \mathrm{hr}$.

As can be seen from Eq. (A-9), the amount of testing to assure a chance failure reliability of 0.99997 becomes impractically large.

\section{Conclusions}

The analysis of reliability-testing data requires that one distinguish between chance and wearout failures. The usual practice in designing for a high reliability is to design equipment so that the mean wearout life is greater than the mission duration plus at least four standard deviations. In testing the equipment for chance failures, then, the equipment is removed from test or overhauled and returned to test at time $t=M-3 \sigma$ when wearout starts to become apparent. This assures that the failures observed during test are chance failures.

In the case of the nuclear rocket, designing the core for a very long wearout life, and hence a negligible probability of failure by wearout, is probably a luxury which cannot be afforded. Component de-rating to obtain the longer wearout life gives a performance penalty which is not permissible. It is concluded that reliability-testing programs, at best, will give assurance that the rocket has a reasonably high wearout reliability. Complete testing programs to assure an equivalent chance-failure reliability appear to be impractical in terms of number of tests and time. However, as shown by the foregoing calculations, some conclusions can be drawn about the chance-failure reliability from the wearout tests.

There is a very significant saving by testing the individual fuel elements in the rocket core. For example, full-core test requirements (1000 elements as sumed) for a reliability of 0.95 at $90 \%$ confidence are 3 tests with $\widehat{\mathrm{M}}=2.6 \mathrm{hr} \pm 10 \%$, or 5 tests with $\widehat{\mathrm{M}}=4.6 \mathrm{hr} \pm 20 \%$ 。 The total test times are 7800 element-hours and 23,000 element-hours, respectively (see Table A-1). Single-element tests for a reliability of 0.97 at $90 \%$ confidence, on the other hand, require, say, 30 tests with $\widehat{M}=1.7 \mathrm{hr} \pm 10 \%$ or 30 tests with $\widehat{M}=6.5 \mathrm{hr} \pm 20 \%$ (see Table A-2). The total test times are 52 element-hours and 196 element-hours, respectively. This gives reduction factors of $7800 / 52=150$ and $23,000 / 196=118$ in the quantity of hydrogen required for the testing. Likewise, the number of fuel elements that must be fabricated is reduced from 3000 and 5000 to 30 . Although core reliability can be assured with greatly reduced number of elements and quantity of hydrogen, there are difficulties in interpreting single-element tests in terms of the whole core performance. In the foregoing analysis it is assumed that the performance of elements in 
individual tests will be identical with their composite performance in a complete core. The validity of this assumption obviously rests on the design of the single-element tests.

\section{REFERENCES}

1. Hansen, G. E., and Roach, W. A., Six and Sixteen Group Cross Sections for Fast and Intermediate Critical Systems, LAMS-2543 (Dec 6, 1961).

2. Oak Ridge National Laboratory, Beryllium Oxide Meeting, TID-7602 (Part 1, Rev) (Dec 1960).

3. General Atomics Division, General Dynamics Corporation, Advanced Beryllium Oxide Concepts Progress Report, GA-3783 (Jan 17, 1963).

4. Hazelwood, R. Nichols, et al., Development and Maintenance of Satellite Systems, Aerospace Engineering 21, No. 4 (April 1962).

5. Bazovsky, Igor, Reliability Theory and Practice, Prentice-Hall, New Jersey (196 I).

6. Burington, R. S., and May, D. C., Handbook of Probability and Statistics with Tables, Handbook Publishers, Inc., Sandusky, Ohio (1953).

7. Fisher, R. A., and Yates, F., Statistical Tables for Biological, Agricultural and Medical Research, Fifth Edition, Oliver and Boyd, London (1957). 